\title{
Mexico: Financial System Stability Assessment Update, including Summary Assessments on the Observance of Financial Sector Standards and Codes on the following topics: The Basel Core Principles for Effective Banking Supervision, and the IOSCO Objectives and Principles of Securities Regulation
}

The update to the Financial System Stability Assessment on Mexico was prepared by a staff team of the International Monetary Fund and the World Bank as background documentation for the periodic consultation with the member country. It is based on the information available at the time it was completed on August 4, 2006. The views expressed in this document are those of the staff team and do not necessarily reflect the views of the government of Mexico or the Executive Board of the IMF.

The policy of publication of staff reports and other documents by the IMF allows for the deletion of market-sensitive information.

To assist the IMF in evaluating the publication policy, reader comments are invited and may be sent by e-mail to publicationpolicy@imf.org.

Copies of this report are available to the public from

International Monetary Fund $\bullet$ Publication Services

700 19th Street, N.W. • Washington, D.C. 20431

Telephone: (202) 6237430 • Telefax: (202) 6237201

E-mail: publications@imf.org • Internet: http://www.imf.org

Price: $\$ 18.00$ a copy

\section{International Monetary Fund}

Washington, D.C. 



\title{
INTERNATIONAL MONETARY FUND
}

\section{MEXICO}

\section{Financial System Stability Assessment Update}

\author{
Prepared by the Monetary and Financial Systems and Western Hemisphere Departments \\ Approved by Ulrich Baumgartner and Anoop Singh
}

August 4, 2006

This report is based primarily on work undertaken during a visit to Mexico from February 22 to March 7, 2006, as part of the Financial Sector Assessment Program (FSAP) Update. The FSAP findings and recommendations were discussed with the authorities during the Article IV Consultation mission in May 2006. The FSAP team was co-led by Alfredo M. Leone (IMF) and Augusto de la Torre (World Bank), and comprised Jorge Cayazzo, Jorge Chan-Lau, Marco Espinosa-Vega, Jan Woltjer (all IMF); Mario Guadamillas, Britt Gwinner, Gregorio Impavido, Emanuel Salinas, Constantinos Stephanou (all World Bank); Jonathan Katz (securities expert, formerly with the U.S. Securities and Exchange Commission); Rudolph Zepeda (Directing Bank Examiner, U.S. Federal Reserve Bank of Atlanta); Ruth de Krivoy (former Governor of the Central Bank of Venezuela); and Solange Bernstein (Superintendent of Pension Funds Administrators of Chile). Pierre Papadacci and Sonia Echeverri (both IMF), and Martin Naranjo (World Bank) assisted the mission. The main findings are:

- Helped by good macroeconomic policies, sound oversight, and a favorable external environment, the already sound Mexican financial system continues to increase its resilience. Although consumer and mortgage lending has been growing at a rapid pace, credit to the private sector remains low by some international comparisons.

- Most shortcomings identified during the 2001 FSAP have been addressed, but a number of supporting reforms are needed to boost efficiency in the financial system and to consolidate its stability.

- $\quad$ Key challenges for the authorities are: (a) entrenching stability by further strengthening prudential supervision and regulation, including by establishing full autonomy of the supervisory agencies, implementing full-fledged consolidated supervision of financial conglomerates, and enhancing monitoring of consumer and mortgage credit; (b) extending the reform and rationalization of development banks; and (c) continuing to promote wider and more efficient private sector access to finance including by fostering transparency and competition.

The main authors of this report are Alfredo M. Leone and Marco Espinosa-Vega, with contributions from other team members.

FSAPs are designed to assess the stability of the financial system as a whole and not that of individual institutions. They have been developed to help countries identify and remedy weaknesses in their financial sector structure, thereby enhancing their resilience to macroeconomic shocks and cross-border contagion. FSAPs do not cover risks that are specific to individual institutions such as asset quality, operational or legal risks, or fraud. 
Glossary

Executive Summary.

I. Macrofinancial and Institutional Setting ..............................................................

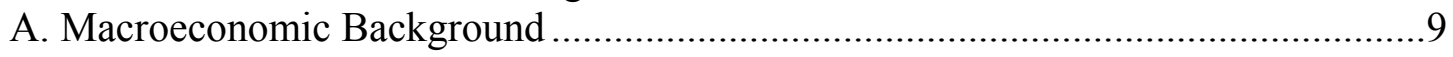

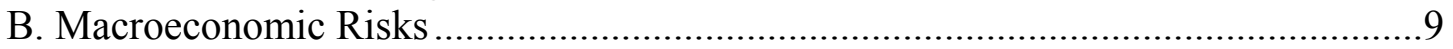

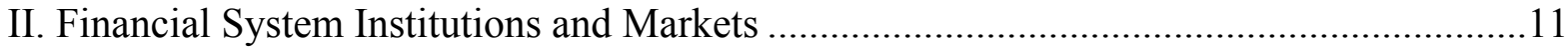

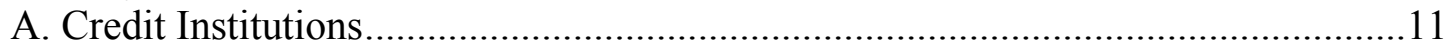

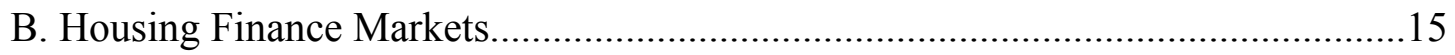

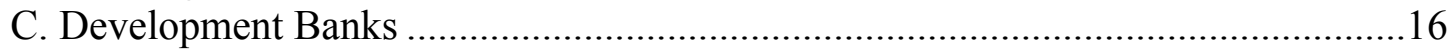

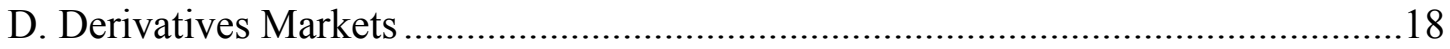

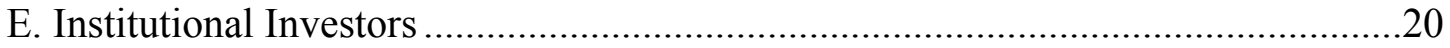

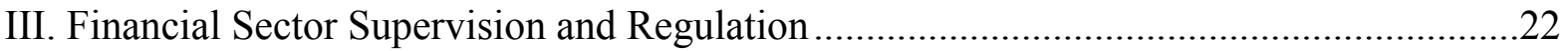

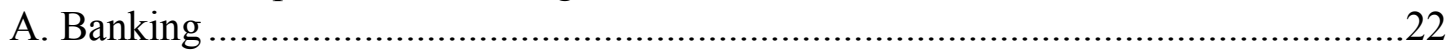

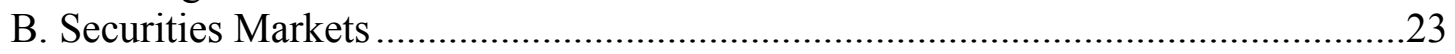

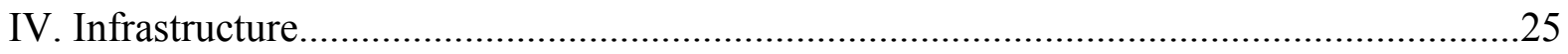

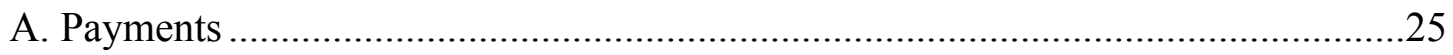

B. Anti-Money Laundering and Combating the Financing of Terrorism

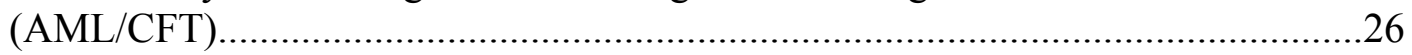

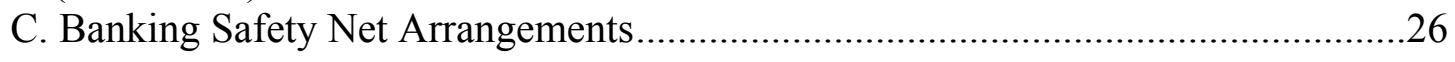

Annex

Observance of Financial Sector Standards and Codes-Summary Assessments.....

Tables

1. Selected Economic Indicators, 1998-2006 ................................................................29

2. Financial Soundness Indicators for Commercial Banks, 2000-06 .................................30

3. Regional Comparison of Equivalent Fees Over Assets, 2005 ........................................ 31

4. Recommended Action Plan to Improve Compliance with the Basel Core Principles .........37

5. Recommended Action Plan to Improve Implementation of the IOSCO Objectives

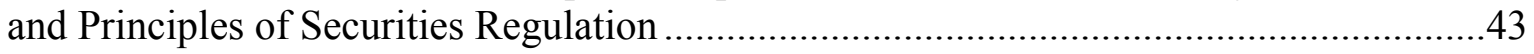

6. Interest Rate, Exchange Rate, Credit Risk Sensitivity Tests, and Credit Risk "Tequila" Scenario, Effects on the Capital Adequacy Ratio....

7. Interest Rate, Exchange Rate, Sovereign Risk, Credit Risk Sensitivity Analysis and "Peer" Scenario, Effects on the Capital Adequacy Ratio ............................58

8a. Market Risk Under a "Tequila” Scenario, Effects on the Capital Adequacy Ratio...........59

8b. Market Risk Under an "Oil Crisis" Scenario, Effects on the Capital Adequacy Ratio .....59

9a. Assumptions for Market Risk "Tequila” Scenario.......................................................60

9b. Assumptions for Market Risk “Oil Crisis” Scenario ...................................................61

10. Shocks on Premiums, Return and Loss Rate, and Scenarios, Effects on the Solvency Ratio 
Figures

1. The Extension of the Domestic Yield Curve ................................................................. 10

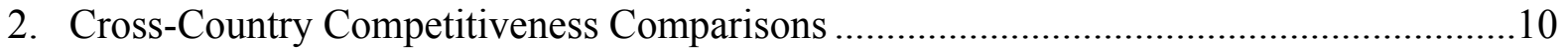

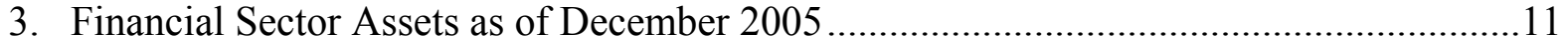

4. Selected Financial Soundness Indicators for Commercial Banks.....................................12

5. Total Financing to the Nonfinancial Private Sector........................................................ 13

6. Implied Volatility in Mexican Peso-U.S. Dollar Options with Different Maturities ........18

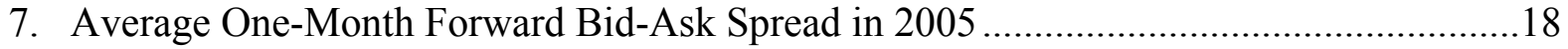

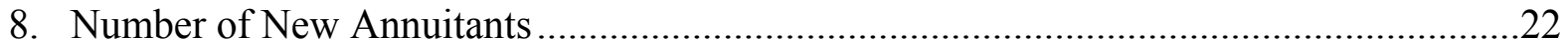

9. Asset/Liability Ratio for Commercial Banks................................................................53

Boxes

1. Key FSAP Update Recommendations ..................................................................

Appendixes

I. Key Milestones in the Reform of the Financial Sector $(2001-2006)$..............................46

II. Detailed FSAP Update Recommendations .................................................................49

III. Stress Analysis for Commercial Banks, the Insurance Sector,

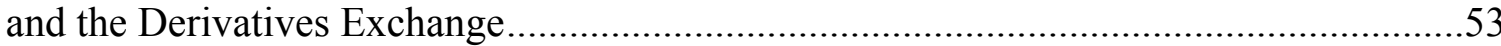

IV. Payments and Securities Settlement Issues .......................................................63 


\section{GLOSSARY}

\begin{tabular}{|c|c|}
\hline $\mathrm{ACH}$ & Automatic clearing house \\
\hline AFOREs & Private pension fund administrators \\
\hline AMAII & Association of Independent Investment Advisors \\
\hline AMIB & Asociación Mexicana de Intermediarios Bursátiles \\
\hline AML/CFT & Anti-Money Laundering and Combating the Financing of Terrorism \\
\hline ASIGNA & Stock exchange clearing fund \\
\hline BANSEFI & Financial Services and National Savings Bank \\
\hline $\mathrm{BCP}$ & Basel Core Principles for Effective Banking Supervision \\
\hline Bolsa & Stock exchange \\
\hline BOM & Bank of Mexico \\
\hline CAR & Capital Adequacy Ratio \\
\hline $\mathrm{CCP}$ & Central Clearing Counterparty \\
\hline $\mathrm{CCV}$ & Central Counterparty for Equity Clearance and Settlement, a subsidiary of INDEVAL \\
\hline CECOBAN & Banking Clearing Center \\
\hline CNBV & National Banking and Securities Commission \\
\hline CNSF & National Insurance and Sureties Commission \\
\hline COFEMER & Federal Commission for Regulatory Improvement \\
\hline CONDUSEF & Consumer Protection Agency \\
\hline CONSAR & Pension Fund Commission \\
\hline CPSIPS & Core Principles for Systemically Important Payment Systems \\
\hline CPSS & Committee on Payment and Settlement Systems \\
\hline DA & Development agency \\
\hline DB & Development bank \\
\hline DRM & Depósito de Regulación Monetaria \\
\hline EFT & Electronic fund transfer \\
\hline FATF & Financial Action Task Force \\
\hline FOVISSSTE & Housing Fund of the Social Security Institute of Public Sector Workers \\
\hline FSAP & Financial Sector Assessment Program \\
\hline FSC & Financial Stability Committee \\
\hline IAS & International Accounting Standards \\
\hline IMCP & Mexican Institute of Public Accountants \\
\hline IMF & International Monetary Fund \\
\hline IMSS & Mexican Institute of Social Security \\
\hline INDEVAL & Securities Depository \\
\hline INFONAVIT & Institute of the Workers National Housing Fund \\
\hline IOSCO & International Organization of Securities Commission \\
\hline IPAB & Institute for the Protection of Bank Savings \\
\hline ISA & International Standards on Audit \\
\hline LIC & Law of Credit Institutions \\
\hline LMV & Securities Markets Law \\
\hline LSM & Mexican Corporation Law \\
\hline MBS & Mortgage-backed securities \\
\hline MexDer & Mexico's Derivatives Market \\
\hline MOUs & Memoranda of Understanding \\
\hline OTC & Over-the-counter \\
\hline $\mathrm{P \& A}$ & Purchase (of assets) and Assumption (of deposit liabilities) \\
\hline
\end{tabular}




\begin{tabular}{|l|l|}
\hline PCAs & Prompt corrective actions \\
\hline POS & Point of Sale \\
\hline RCV & Pension account managed by AFOREs (Retiro, Cesantia y Vejez) \\
\hline SAPI & $\begin{array}{l}\text { Investment promotion vehicles aimed at facilitating the listing on the stock market of } \\
\text { small- and medium-sized enterprises }\end{array}$ \\
\hline SENICREB & Servicio Nacional de Información de Créditos Bancarios \\
\hline SHCP & Secretariat of Finance and Public Credit \\
\hline SHF & Federal Mortgage Society, a state-owned development bank \\
\hline SIAC & System for Accountholders' Service (Sistema de Atención a Cuentahabientes) \\
\hline SIDV & Sistema Interactivo para el Depósito de Valores (SIDV), a securities settlement system \\
\hline SMEs & Small- and medium-sized enterprises \\
\hline Sofoles & Nondeposit-taking specialized credit institutions \\
\hline Solvency II & $\begin{array}{l}\text { EU Commission project aimed at reforming the EU solvency system for insurance } \\
\text { companies }\end{array}$ \\
\hline SPEI & A modern hybrid system (Sistema de Pagos Electrónicos Interbancarios) \\
\hline SPEUA & Sistema de Pagos Electrónicos de Uso Ampliado \\
\hline SRO & Self-regulatory organization \\
\hline TIIE & Tasa de Interés Interbancaria de Equilibrio, benchmark in the interbank money market \\
\hline VaR & Value at Risk \\
\hline
\end{tabular}




\section{EXECUTIVE SUMMARY}

The Mexican banking system is sound and has strengthened considerably in recent years. Overall, private banks are profitable and well-capitalized. In recent years, some development banks (DBs) have also reported adequate capital positions and positive results. The system has benefited from the current economic recovery, which has boosted credit demand while contributing to a steady improvement in banks' asset quality. Markets for derivatives (both over-the-counter (OTC) and exchange-traded) have grown significantly, allowing for better management of market risks.

The 2001 FSAP found that while sound macroeconomic policies and bank restructuring had contributed to a more resilient financial system, a number of shortcomings remained. In particular, insolvent banks could access the Bank of Mexico (BOM)'s liquidity support; there was no system of prompt corrective actions; the bank resolution framework was weak; there were serious deficiencies in the financial performance of development banks; housing finance required an overhaul; financial sector supervision required strengthening; and regulatory agencies lacked adequate autonomy.

Since then, the authorities have introduced a number of key reforms to consolidate financial stability (Appendix I), including:

- Major improvements in compliance with the Basel Core Principles for Effective Banking Supervision (BCP) and the implementation of IOSCO Principles and Objectives of Securities Regulation. In particular, the legal and regulatory framework was strengthened, progress was made toward risk-based supervision, and the professionalism of the National Banking and Securities Commission (CNBV) was enhanced. Regarding securities regulation, the legal authority of the CNBV was expanded and transparency and market infrastructures were improved.

- Removal of the significant shortcomings in payment systems identified at the time of the 2001 FSAP. The uncollateralized BOM credit lines and guarantees were virtually eliminated, the legal basis for payments and clearing and settlement was substantially improved, and the oversight powers of the BOM were adequately clarified.

- Increased competition among the private managers of the defined-contribution pension funds. Policies aimed at loosening barriers to entry and facilitating migration to lower fee funds have made the market more contestable. Although still high, fees have decreased and expected replacement rates have increased.

- State-of-the-art regulation and supervision of the insurance industry. Regulation and supervision for the insurance industry have been significantly strengthened in line with the 2001 FSAP recommendations.

- Major improvements in the housing finance market. In the aftermath of the 1994-95 "Tequila" crisis, commercial banks retreated from the mortgage business. 
The Federal Mortgage Society (SHF), a specialized housing development bank, bridged the gap. Furthermore, an industry of private mortgage originators (Sofoles) has expanded rapidly. While still reliant on SHF's funding, Sofoles have started tapping the market directly and mortgage-backed securities (MBS) are emerging. Achieving the 2009 "sunset clause" for second-tier financing by SHF of housing lending is paramount for the development of private mortgage markets.

- $\quad$ Significant progress regarding the banking safety net. The prompt corrective actions (PCAs) in place meet international best practices, and the recent changes to the banking law to deal with insolvent commercial banks represent significant improvements. However, bylaws need to be amended as soon as possible to make the new resolution clauses fully implementable. There is also a need to establish a framework and operational guidelines for the resolution of financial groups.

- A proposed law now in congress is intended to address the shortcomings identified during the second mutual evaluation of anti-money laundering practices in Mexico. In 2003-04, the Financial Action Task Force (FATF) found Mexico to be not fully compliant with several recommendations, namely: terrorist financing was not criminalized; there was no provision for freezing, seizing, or confiscating terrorist assets; financial institutions were not required to report suspicious transactions related to terrorist financing; and financial secrecy obstructed access to financial information by prosecutors. ${ }^{1}$ Since then, the Mexican Senate approved a law penalizing terrorism financing and forwarded it to the Chamber of Deputies.

The key remaining challenges are to further entrench stability and to promote wider and more efficient private sector access to financing. Recommended priority actions include achieving full autonomy of the supervisory agencies, subject to adequate accountability; implementing full-fledged consolidated supervision of financial conglomerates; extending the reform and rationalization of development banks; and promoting greater competition across different credit providers while continuing to monitor the risks associated with the rapid growth in consumer and mortgage lending. In the securities markets, there is a need to further improve the transparency and due process protections in the disciplinary process, and upgrade auditing standards. Regarding deposit insurance, the authorities could consider market discipline-supporting measures such as a reduction in coverage and the charging of risk-based premiums. Finally, there is a need to

\footnotetext{
${ }^{1}$ It used the 2002 Anti-Money Laundering/ Combating the Financing of Terrorism (AML/CFT) methodology endorsed by FATF and the IMF, and reviewed Mexico's compliance with the revised FATF 40+9 Recommendations.
} 
introduce interagency contingency planning and develop internal protocols regarding emergency liquidity assistance. A list of the key FSAP Update recommendations is presented in Box $1{ }^{2}$

\section{Box 1. Key FSAP Update Recommendations}

- Reinforce the monitoring of credit risks associated with consumer and mortgage lending. ST 1/

- Further strengthen consolidated supervision of financial conglomerates. ST

- Reassess the mandates, functions, and instruments of development banks. ST

- Establish full autonomy of supervisory agencies, subject to adequate accountability standards. ST

- Establish plans for orderly consolidation of mortgage Sofoles once the SHF stops second-tier lending to them. MT

- Maintain the 2009 sunset date for the state-owned SHF second-tier lending to fund middle- and high-income housing. MT.

- Introduce interagency contingency planning and develop internal protocols regarding emergency liquidity assistance. ST

- Promote greater competition among different credit providers by the timely disclosure of standardized interest rate indicators for different loan products; and improve the registry systems and contract enforcement environments across state jurisdictions. ST

- Carry out self-assessment of SIAC and SPEI regarding observance of the CPSS CPSIPS. Also, carry out self-assessments of the SIDV and the two Central Clearing Counterparties (CCPs) regarding observance of CPSS/IOSCO recommendations. ST

- Promote competition on net returns in the private pension system and resolve the impasses regarding disability benefits that have stalled the development of the annuities market. ST

- Consider market discipline-supporting measures for deposit insurance such as a reduction in coverage and the charging of risk-based premiums. ST

- Establish an effective framework for the liquidation of banks and enable partial deposit transfers under Purchase and Assumption (P\&As). ST

- Seek a suitable formula to improve the financial condition of the Institute for the Protection of Bank Savings (IPAB), including the transferring of its debt to the federal government. MT 2/

- Further foster interoperability and economies of scale in retail payment systems. MT

$1 / \mathrm{ST}=$ Short term

2/ MT $=$ Medium term

\footnotetext{
${ }^{2}$ A detailed list of recommendations is presented in Appendix II.
} 


\section{MACROFinAnCial ANd InStitutional Setting}

\section{A. Macroeconomic Background}

1. Policies implemented over the last decade have strengthened economic fundamentals and brought macroeconomic stability. As indicated in the staff report for the Article IV consultation, fiscal consolidation has put the public debt ratio on a gradually declining trend (gross augmented public debt is now around 45 percent of GDP), and an independent central bank has been able to bring inflation down to about 3 percent in the context of a floating exchange rate regime.

2. The steady drop in inflation and inflation expectations has produced an environment more favorable to economic and financial activity. Benefits include lower interest rates, increased financial intermediation, a rebirth of the fixed nominal interest rate mortgage market, increased access to credit, a dedollarization of credit markets, lower costs of government debt servicing, and an extended yield curve providing the foundations for a deeper domestic capital market (Figure 1). In turn, these financial developments should facilitate private fixed investment and economic growth.

3. A proactive debt management strategy has also contributed to the stability of the country. By shifting the structure of its debt away from foreign currency-denominated instruments, the government has reduced vulnerability to sharp exchange rate fluctuations. The government debt management program has also supported the extension of the yield curve, and contributed to deeper and more liquid secondary securities markets. These improvements have contributed to Mexico's achievement of investment-grade rating, uninterrupted access to capital at low cost, and resilience to global financial shocks, such as the financial stress of the 1998 Russian crisis and the 2001-02 worldwide recession.

4. However, with an incomplete reform agenda, Mexico has not yet been able to achieve rapid economic growth (Figure 2). As analyzed in the Article IV staff report, growth is held back by relative weaknesses in the business and investment environment, as well as in market flexibility and competition. Reforms remain pending in key sectors, including labor and energy. As a consequence, economic growth has yet to boom in spite of a favorable external environment including high oil export prices and significant global liquidity. Average 2001-05 real GDP growth was only about 2 percent; although growth is expected to reach 4 percent in 2006, it is expected to moderate to 3.5 percent in 2007 (Table 1).

\section{B. Macroeconomic Risks}

5. Main macroeconomic risk factors relate to the links with the U.S. economy and potential pressures on public finances arising from the external environmentincluding global liquidity conditions and oil export revenues. A slowdown in U.S. industrial production would have an adverse effect on domestic economic activity and as a result, on credit demand, and bank asset quality. Mexico's low external current account deficit and external financing needs make the country less vulnerable to a deterioration of 
external financing conditions than some other emerging economies. However, the fiscal accounts rely on oil revenue and, in the absence of offsetting fiscal adjustment, adverse developments in the oil sector could result in increased borrowing requirements with crowding out effects and implications for the sustainability of public debt. Although progress has been made in extending the maturity and duration of government domestic debt, a considerable share is still of short remaining maturity or interest-rate indexed, making Mexico vulnerable to a tightening of global liquidity and sharp increases in interest rates. In principle, this debt structure raises the possibility of "snowballing" government financing needs, and a deterioration of public sector default risk. This could affect banks given that their exposure to the public sector, although declining, still remains at about half of their earning assets. ${ }^{3}$

\section{The high rates of growth in consumer and mortgage lending could, without} proper monitoring, raise macroeconomic concerns in the future. For now, household debt remains relatively contained, but further rapid growth of such debt could weaken this sector's debt service capacity with a consequent deterioration in the quality of households' creditors. The need of these credit institutions to address nonperforming loans could, in turn, reduce overall credit to the private sector and contribute to an economic downturn.

\section{Also, Mexico's existing sound oversight and regulatory practices are vulnerable}

to reversal with potential negative macroeconomic implications. This vulnerability arises mainly from the lack of full autonomy of the regulatory agencies. Without full autonomy, regulatory agencies could one day be forced into regulatory forbearance policies that contributed to a sudden deterioration in credit quality and an unsustainable credit boom, with adverse macroeconomic consequences.

Figure 1. The Extension of the Domestic Yield Curve

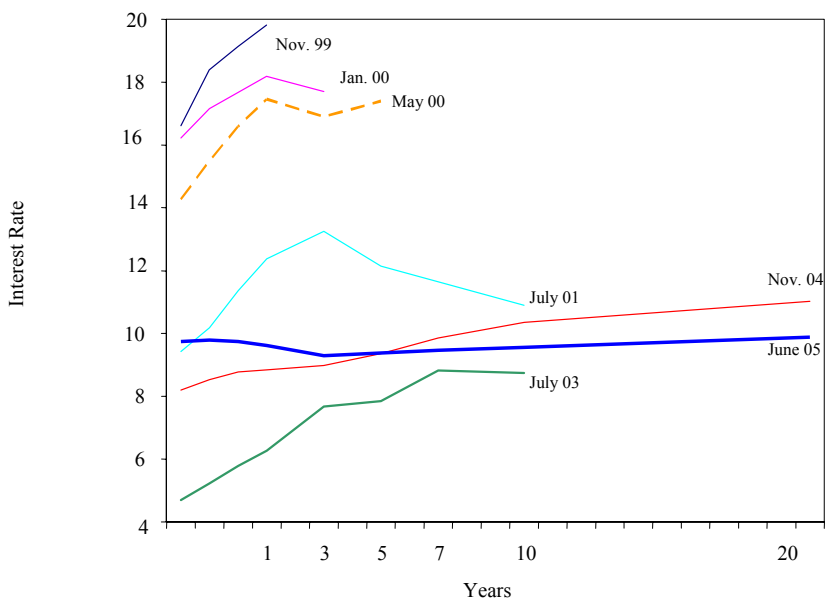

Sources: Mexican authorities and Staff calculations
Figure 2. Cross-Country Competitiveness Comparisons

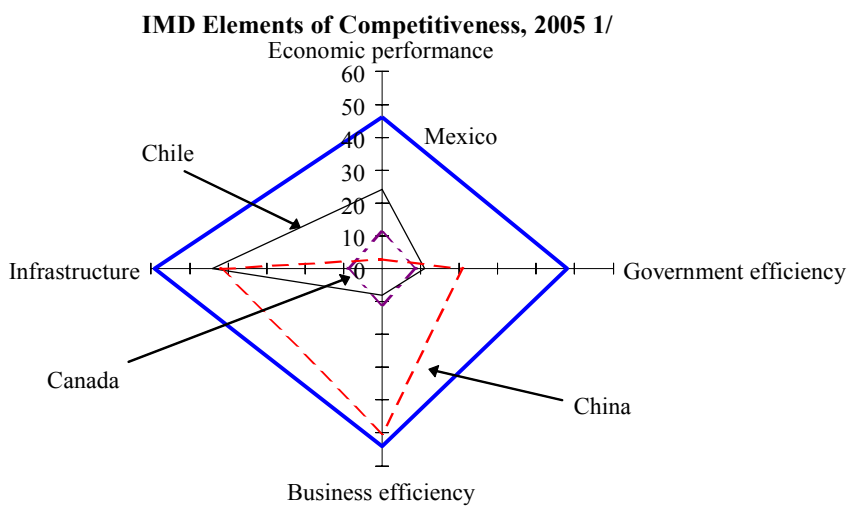

1/ Rank in survey out of 60 countries. Source: International Institute for Management Development (IMD).

\footnotetext{
${ }^{3}$ Excluding repo operations the commercial bank exposure to the public sector is lower (around 30 percent).
} 


\section{FinANCIAL SySTEM InSTITUTIONS AND MARKETS}

8. The financial system is diverse, but dominated by large foreign-owned financial conglomerates. The system includes commercial banks, insurance companies, pension funds, broker dealers, investment banks, development banks, non bank financial institutions (Sofoles), securities firms, and leasing and factoring companies (Figure 3). Sofoles do not take deposits and are licensed by the Secretariat of Finance and Public Credit (SHCP) to grant credit to specific segments of the economy. The financing of mortgage Sofoles comes from different sources, including the SHF. The Sofoles have also started to tap the private market and, recently, a few of the large mortgage Sofoles have been acquired by private banks. Large, multinational financial groups are involved in almost all the salient lines of financial business - with the exception of insurance - and dominate the financial landscape.

Figure 3. Mexico: Financial Sector Assets as of December 2005

$$
\text { (In percent) }
$$

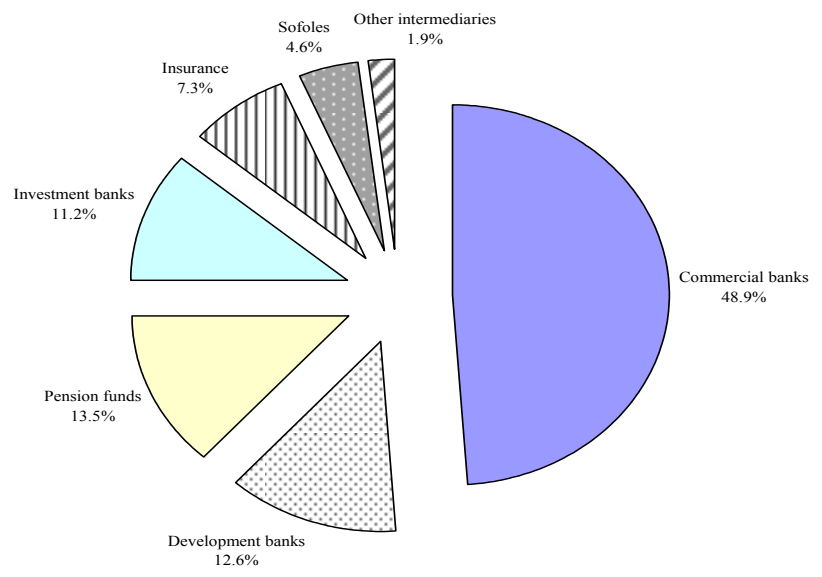

Sources: CNBV, CNSF and CONSAR.

\section{A. Credit Institutions}

9. Concentration and globalization have characterized the commercial banking system. The banking sector exhibits a significant degree of concentration (the three largest institutions account for close to 60 percent of the banking sector's assets) and a high degree of foreign ownership (representing close to 80 percent of all banking assets as of December 2005).

\section{Competition on prices and quality of services among financial intermediaries} needs to be fostered further for the users of financial services to fully benefit from efficiency gains. Because concentration may sometimes reduce competition, it is important to enhance efforts to promote competition by: (a) fostering consumer mobility; (b) preventing collusive practices; (c) relaxing entry barriers; and (d) leveling the playing field. 


\section{The Mexican banking system has strengthened considerably in recent years.}

Private banks are overall profitable and well-capitalized. Minimum capital requirements are set at 8 percent of risk-weighted assets, but overall banks hold significantly more capital than the minimum required (Figure 4). The system overall has benefited from the current economic recovery, which boosted credit demand while contributing to a steady improvement in banks' asset quality (Table 2, Figure 4). Rapid loan growth has yet to affect bank asset quality, which improved significantly in recent years. Nonperforming loans (NPLs) are low at less than 2 percent of gross loans, down from close to 6 percent in 2000. Banks have also built sizeable provisions against NPLs, with coverage ratios over 200 percent (due in part to tax incentives).

Figure 4. Mexico: Selected Financial Soundness Indicators for Commercial Banks

Capital Adequacy and Loan Quality

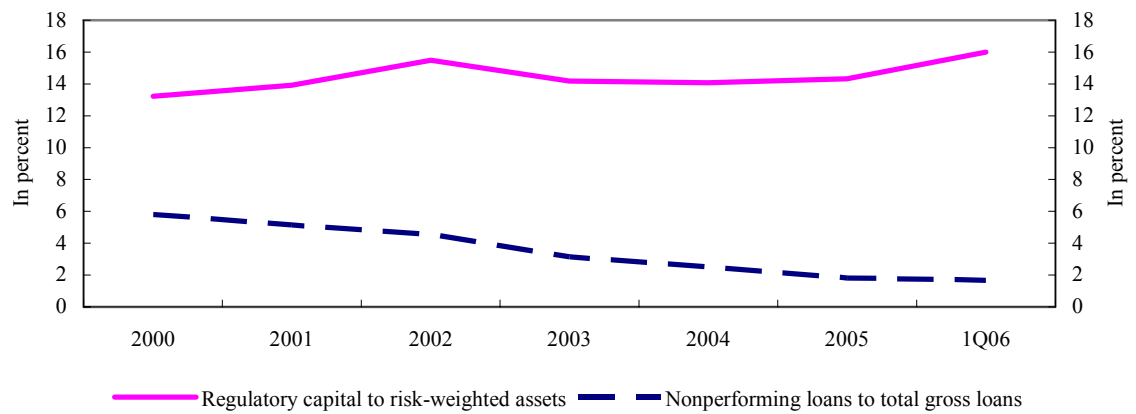

Profitability

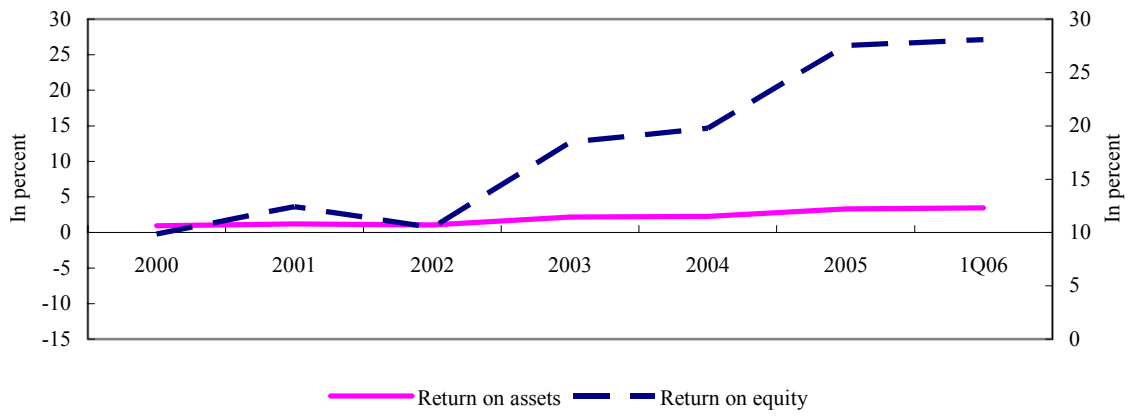

Liquidity

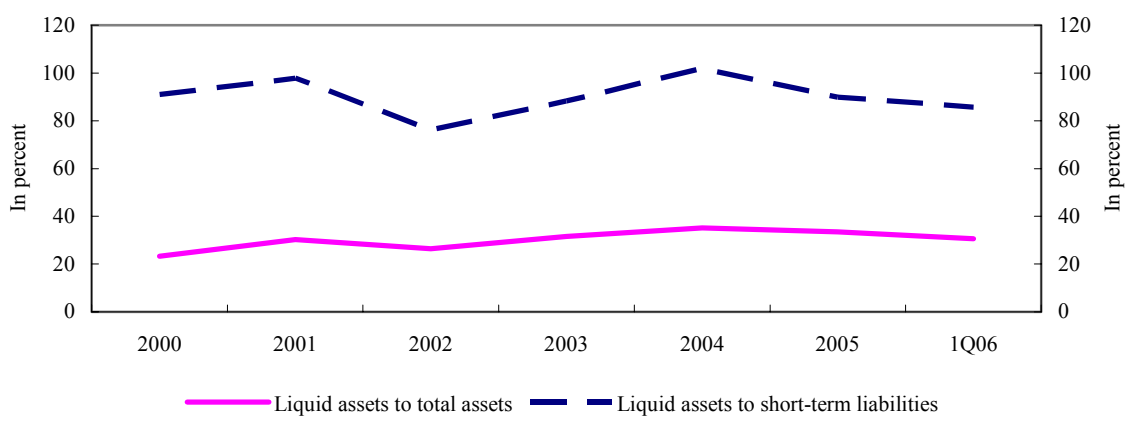

Source: CNBV. 


\section{Commercial banks remain the primary source of financing to the nonfinancial}

private sector. Total financing to the private sector, as a fraction of GDP, increased by about 2 percent since 2000 (Figure 5). ${ }^{4}$ Commercial banks accounted for over a third of this financing, with credit representing about 50 percent of their assets at end-2005. The composition of banks' private loan portfolio has recently shifted toward consumer credit at the expense of commercial lending. This shift has coincided with an increase in domestic suppliers' credit. ${ }^{5}$

Figure 5. Mexico: Total Financing to the Nonfinancial Private Sector (In percent of GDP)

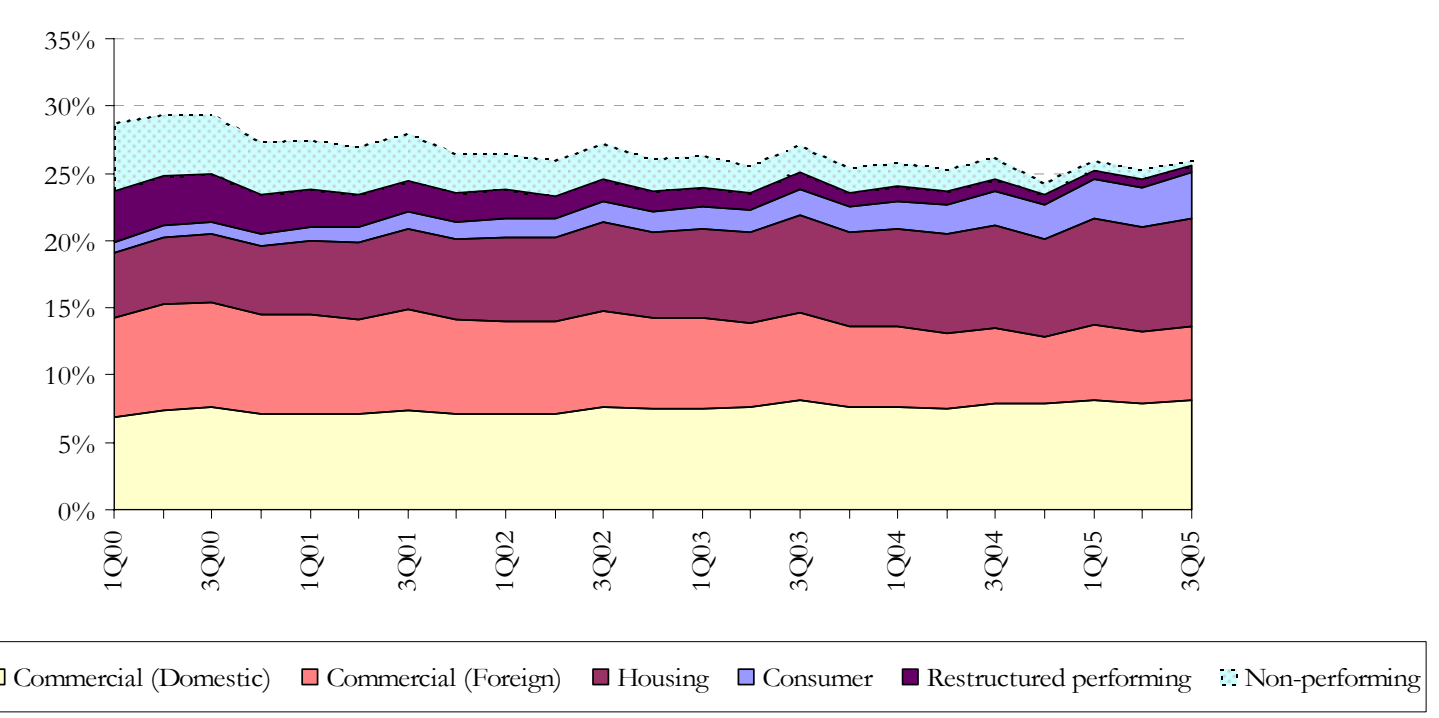

Sources: BOM, INEGI.

Note: Excluding equity financing and certain public sector retirement programs financing mortgages (e.g., FOVISSSTE). Commercial, housing and consumer financing include only performing credit. Domestic bond issuance only includes bonds issued by nonfinancial private sector.

\section{Banking system stability analysis}

\section{Since 2001, risk management practices in systemically important commercial} banks have strengthened substantially. The risk management units of these banks appear to be independent of their treasuries and monitor liquidity risk under normal and stress scenarios, laying the ground work for prudent lending and investment activities, and strong

\footnotetext{
${ }^{4}$ It is important to note that since 2000 there has been a substitution of external financing by domestic commercial financing and a significant expansion of consumer financing. In fact, domestic financing to the private sector has increased by almost 4 percent of GDP since 2000 .

${ }^{5}$ Issues of peso-denominated securities by nonfinancial private corporates have increased significantly over the past five years. These issues have increased from about US\$700 million in 2000 to about US\$2.5 billion in 2005. However, only large high quality corporates can tap the bond market and equity issuance has remained small.
} 
internal controls. These banks monitor risk taking, including with Value at Risk (VaR) and back-testing analysis to help set limits to lines of business, and to generate early warning systems and triggers. The risk management practices of systemically important commercial banks are supported by internal models, reputable specialized vendors, and their foreign headquarters (where applicable).

\section{Stress tests were carried out to assess banks' resilience to a variety of shocks.} The stress tests were carried out in parallel by BOM and CNBV and the methodologies and shocks were chosen in consultation with the FSAP team. The shocks were based on historical stress scenarios, periods of heightened volatility, and historical distributions of key macro variables for peer economies.

\section{The stress tests suggest that the banking system is resilient to market risk}

shocks. BOM and CNVB performed market risk analysis of the banking system based on large single-factor shocks (Appendix III presents more details). Individual shocks included a depreciation and appreciation of the peso exchange rate against the U.S. dollar, parallel shifts in the term structure of interest rates, and an inversion of the yield curve. In addition to these shocks, CNBV tracked the impact of a sovereign risk shock, and a drop in domestic equity prices on commercial bank trading books. The results suggest that, as of December 2005, exchange rate risk is not the main market risk. On average, a shock to sovereign risk which was proxied by a $180 \mathrm{bp}$ increase in the EMBI, did not have an appreciable impact on the system's CAR either. The most relevant shock to the banking system appears to be a sharp upward parallel shift in the yield curve (Tables 6 and 7) where one bank's capital drops below the regulatory CAR.

\section{Banks were able to withstand "Tequila" and "Oil" scenarios analyzed by CNBV}

to assess market risk. The exercises consisted of assessing the sensitivity of all of the banking sector's trading books to valuation changes of simultaneous financial shocks (including inflation, domestic and international equity prices, and interest rates (Tables $8 \mathrm{a}$ and $8 \mathrm{~b}$ ). The shocks were calibrated proportionally to those observed up to 12 months from the onset of the 1994-95 crisis, and the sharp 1997-98 oil price drop. Because of the severity of the scenario, bank's capital would be affected more under the "Tequila" than under the oil scenario. Regardless of the shocks analyzed, the largest (and most profitable) banks would be affected proportionally more than other banks, although their capital adequacy ratio would never drop below the regulatory CAR (due in part to banks' active use of hedging strategies). In the most extreme scenario, on average, large commercial banks lost 40 percent of regulatory capital.

17. Banks also appear resilient to credit risk shocks. In order to evaluate credit risk, BOM assessed the impact on the portfolios of the banking sector of an increase in corporate default rates calibrated to those observed during the 1994-95 crisis and tracking the cumulative losses for the next six months. Analysis of the CAR computed considering the six month cumulative expected losses (to match the peak of the 1994 crisis) shows that at the peak of the stress event (six months after the initial stress trigger), two small banks could see their CAR falling under the regulatory 8 percent (Table 6). 
18. Commercial banks' exposure to the public sector, has been declining recently, but still amounts to about half of commercial banks' earning assets. In addition to making banks sensitive to potential changes in the value of government securities, these claims can contribute to higher financing costs and crowd out the private sector. There is a consensus among private analysts that a sudden shock to confidence in the sovereign is unlikely and the results of the sovereign risk shock provide additional comfort. However, the value of government securities remains a function of sustained macro policy discipline.

\section{B. Housing Finance Markets}

19. Since 2001, the government has made impressive progress in establishing the building blocks for private mortgage origination and securitization. The SHF has provided guarantees, created new property appraisal standards, sold mortgage default insurance, and provided funding for mortgage Sofoles. These actions have fostered the standardization of private mortgage origination ${ }^{6}$ and the tapping of private capital markets through mortgage-backed securities.

20. Monitoring of mortgage Sofoles' risks is carried out by the SHF and the market. The CNBV carries out limited supervision of Sofoles. Market discipline applies to Sofoles tapping the markets directly. And as the main creditor to Sofoles, the SHF analyzes their overall financial strength and is aware that more resources need to be devoted to track credit risk. In particular, smaller Sofoles are significantly exposed to residential construction lending, which carries significantly higher credit risk than lending to home owners.

21. After having filled a void, the SHF is scheduled to stop direct financing to mortgage Sofoles. Thanks in part to the SHF, the participation of mortgage Sofoles in outstanding housing loans grew from 6.2 percent in 2000 to 17.3 percent in 2005, and the system-wide mortgage portfolio grew by a cumulative 65 percent between 2000 and 2005, and now stands at 9.6 percent of GDP.

22. The authorities should address shortcomings in the industry infrastructure that could dampen the nascent MBS market. Since 2003, 15 MBS issues worth

MEX \$11.5 billion have come to the market, involving mortgage loans initiated mainly by the larger Sofoles. While noteworthy, this represents only 0.7 percent of the balance of credits outstanding in the system at end-2005. Furthermore, the mission learned of a specific case of unsatisfactory work by auditors, credit rating agencies, and lack of due diligence. ${ }^{7}$ The authorities should enforce due diligence reviews to boost the nascent Mexican MBS market.

\footnotetext{
${ }^{6}$ Middle-income households in Mexico can now obtain peso-denominated 15-year mortgage loans at a fixed nominal interest rate of about 9 percent.

${ }^{7}$ For instance, serious deficiencies were found in a mortgage pool where the SHF was asked to provide mortgage insurance. Thirty percent of the loans suffered from documentation problems. The auditor had reviewed only a small sample of loans. The rating agency did not review any loan files, nor did the institutions that were offering credit enhancements. No firm was called upon to play a specialized diligence role.
} 
23. The two housing funds INFONAVIT (for private employees) and FOVISSTE (for public employees) are key players in the mortgage market. Employees and employers contribute to these funds. ${ }^{8}$

24. Both institutions keep an account for every worker which is used to finance a down payment for a housing credit, to pay off such credit, or if available for withdrawal at retirement. INFONAVIT's dominance of the primary mortgage market has increased from 49 percent of outstanding balances in 2000 to 60 percent at the end of 2005 . At the same time, INFONAVIT has substantially improved its management, operations, and corporate governance. ${ }^{9}$ INFONAVIT's cash flows are increasingly made up of loan collections and less of mandatory contributions.

25. INFONAVIT has widened its cooperation with the private sector. It now allows its members to leverage their INFONAVIT savings to obtain market-based mortgage finance. Additionally, it has implemented new, more efficient systems and processes for mortgage origination and servicing, which has substantially reduced NPLs and improved loan collection. It has adopted international accounting standards, and it has put in place executive committees for risk management, auditing, and strategic policy. INFONAVIT also has securitized portfolios, although the securitizations have been expensive, requiring 18-23 percent subordination of the residual certificate for the senior certificates.

\section{Development Banks}

26. The 2001 FSAP emphasized that DBs suffered from an inherent tension between fostering access to financial services for underserviced households and firms, and minimizing losses in their credit activities. Since they took deposits, they also represented an additional source of vulnerability for the financial system. To overcome this tension, the 2001 FSAP recommended a reform strategy based on separating subsidies from finance, consolidating DBs, and gradually transforming them into development agencies (DAs). DAs would be charged with clearly identifying in their charter the underserviced sectors of the economy to be targeted (such as SMEs and low income households) and the supporting mechanisms (e.g., technical assistance and enhancements such as partial guarantees) to be used, thus facilitating accountability. DAs would receive their funding through the government budget, would not take deposits, nor would they issue debt or participate in the payments system.

27. In the last five years, some DBs have been reformed along the lines recommended in the 2001 FSAP. In particular, DBs are now regulated and supervised as private banks; interest rate loan subsidies have been reduced and an increasing share of subsidies is financed through the government's budget; lending by DBs has significantly shifted from direct lending to lending through private financial institutions; partial guarantees have declined (from 80 percent or more to about 50 percent on average). As a result, in

\footnotetext{
${ }^{8}$ The federal government contributes to INFONAVIT's capital as stipulated in its charter (Ley del INFONAVIT).

${ }^{9}$ FOVISSSTE's operational improvements, though not trivial, are much less significant than INFONAVIT's.
} 
recent years, some DBs have reported adequate capital positions and positive results. ${ }^{10}$ However, the depth and breath of reform have been uneven across DBs.

28. The greatest progress has been achieved by DBs operating largely as development agencies. Specifically, Financiera Rural and FIRA have well-defined mandates and are prohibited from taking deposits (Financiera Rural is also prevented from issuing any liability instruments). ${ }^{11}$ They fund their lending activities (which are exclusively second-tier in the case of FIRA) out of their endowments and loan collections, and lend largely at market interest rates. The Financial Services and National Savings Bank (BANSEFI) has the mandate of promoting savings for low-income households and of spearheading the development of credit cooperatives (cajas populares). It administers a one-off government investment subsidy to finance technical assistance to set up a common network and infrastructure and to raise the sector's governance, transparency, and management capacity to standards required for licensing by the CNBV.

29. In the case of other DBs, mandates remain unclear and their initial raison d'être is losing relevance in the face of rapid financial market development. The initial niches of NAFIN, BANCOMEXT, and BANOBRAS (financing of SMEs, export promotion, and sub-sovereigns, respectively) are being eroded by international commercial banks and the capital markets. BANCOMEXT's return to first-tier lending should be financed from the government's budget (rather than via the current cross-subsidization within BANCOMEXT's activities). As the most creditworthy state and local governments increasingly access private financial markets, BANOBRAS is being left with a sub-sovereigns portfolio which creates major challenges to meet its mandate while preserving its capital.

\section{Going forward it is important to:}

- Continue with current plans for establishing a "subsidies bureau" in an effort to rationalize the numerous financial subsidy and guarantee programs;

- Continue with efforts in assessing systematically the net benefits of loan, guarantee, and subsidy programs;

- $\quad$ Continue with the elimination of operations and infrastructures' duplications across DBs;

- $\quad$ Continue with efforts to fully separate subsidies from credit, by moving to marketbased pricing of DB products while ensuring that remaining subsidies are welldesigned, well-targeted, and funded directly from the government budget;

\footnotetext{
${ }^{10}$ The only exception is BANCOMEXT, which continues to make losses on account of its export promotion activities.

${ }^{11}$ Financiera Rural was created after the liquidation of Banrural.
} 
- $\quad$ Subject to a clear definition of objectives and mandate, an SME oriented DA should replace NAFIN and BANCOMEXT. The export promotion of the latter should be financed through the government budget;

- $\quad$ Consider consolidating FIRA and Financiera Rural in a single, rural-oriented DA; and

- $\quad$ Consider transforming BANOBRAS into a DA oriented toward capacity building in state and local governments.

31. As the DB system evolves towards a DA model, there will be a need to reform the way in which DB performance is measured and evaluated using international best practices. The current criteria - of measuring performance in terms of the volume of loan disbursements - is bound to become increasingly less relevant.

\section{Derivatives Markets}

32. The main derivatives market in Mexico is the OTC market, which is globally integrated. Currently, the most traded instruments in this market are currency options, forwards, cross-currency swaps, and peso-denominated interest rate swaps (TIIE-swaps). Currency options have been popular given their declining costs (proxied by implied volatility, Figure 6). By end-2005, the Bank for International Settlements (BIS) estimated that the outstanding notional amount in the OTC market amounted to US\$530 billion. The Mexican OTC market is inexpensive relative to other Latin American countries (Figure 7).

Figure 6. Mexico: Implied Volatility in Mexican Peso-U.S. Dollar Options with Different Maturities
Figure 7. Mexico: Average One-Month Forward Bid-Ask Spread in 2005 (In percent of the ask price)
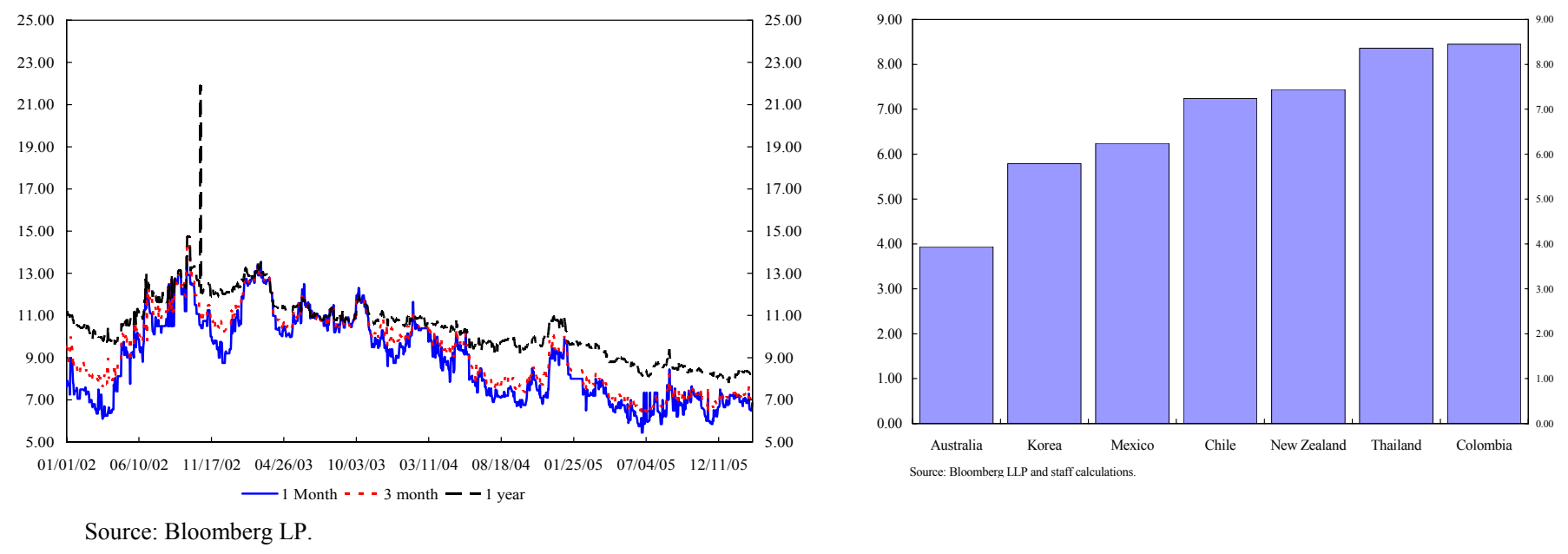

33. The development of the much smaller domestic exchange-traded derivatives market, MexDer, has been less even. MexDer — which is less than one-sixth the size of the OTC market —offers futures on individual equities, equity indices, foreign currencies, and government bonds; and options on equities, equity indices, and on exchange-traded funds. 
While the derivatives exchange grew steadily from 2001 to mid-2004, the notional outstanding amount has shown significant volatility since then. MexDer officials expect this volatility to diminish significantly with the new withholding tax and capitalization rules for local banks and brokers and as institutional investors expand their trading. MexDer has also introduced measures to attract some of the liquidity available to international players through the Chicago Mercantile Exchange, such as the creation of omnibus accounts and the enhancement of its payment settlement system.

34. Recent regulatory changes enabling the participation of AFOREs in repo and securities lending operations are expected to contribute to increasing liquidity in the repo market. However, restricting borrowing of government securities from the BOM to primary dealers, and prohibiting institutional investors, such as pension funds and insurance companies, from lending securities may restrict the development of the repo market.

35. MexDer seems to have implemented an adequate contingency plan to withstand the default of a number of its members via different lines of defense. However, a formal assessment of the risk management structure of the Clearing Fund (ASIGNA), in terms of its observance of the CPSS/IOSCO recommendations for central counterparties, should be carried out by the BOM and the CNBV. ASIGNA acts as a central counterparty for the trades conducted on MexDer.

\section{The following measures could enhance the stability and efficiency of the derivatives market:}

- $\quad$ Streamline the tax law to facilitate the transfer of collateral in case of default of a counterparty to a derivatives transaction. ${ }^{12}$

- $\quad$ Set up the conditions for the development of a credit derivatives market. In particular, improve the availability and quality of credit information on corporations, and harmonize the legal framework governing the recovery process in case of default across jurisdictions and states. This measure would also contribute to the development of the local corporate bond market.

- $\quad$ Authorize insurance companies to use OTC derivatives to hedge their risks. Insurance companies hold long duration portfolios, which could be efficiently hedged using TIIE swaps. However, current regulations prevent them from using derivatives other than those listed in organized exchanges. While MexDer has recently introduced an interest rate swap-like product, this product is more expensive and less liquid than the OTC TIIE swap.

\footnotetext{
${ }^{12}$ Unless a trust is established in connection to the transaction (caución bursátil or prenda de garantía), the transfer of collateral in case of a counterparty default is taxed. Establishing a trust, however, increases transaction costs for contracts written onshore and tilts investors toward the offshore market.
} 


\section{E. Institutional Investors}

\section{Privately managed pension funds}

37. Although the authorities have succeeded in increasing competition on fees in the defined-contribution pension fund industry, fees for asset management remain high. CONSAR, the sector's regulator, has lowered entry barriers and facilitated switches to lowerfee funds. As a result, six new AFOREs entered the market during 2001-05, and migration to lower-fee funds has increased in recent years. However, Mexican equivalent fees over assets, regardless of the time horizon, are above the regional average (Table 3).

38. While the automatic assignment of accounts and disclosure of equivalent fees have enhanced contestability, CONSAR's methodology may need to be re-examined. CONSAR's equivalent fee calculation is valid only for an "average" individual, making it difficult to compare AFOREs' effective fees across participants. In addition, automatically assigned accounts to low-fee AFOREs are likely to be characterized by low balances and low contribution densities, endangering the sustainability of these AFOREs.

\section{CONSAR may wish to consider the following recommendations to further promote competition on fees:}

- $\quad$ CONSAR should consider a shift in focus toward gradually promoting competition on net (ideally, risk-adjusted) returns. Efforts in this direction would be greatly facilitated if the industry were to converge toward a single, asset-based fee structure, as this would make it easy to compare funds by net returns.

- $\quad$ Further simplification and individualization of the ranking of AFOREs according to fees charged by requiring funds to report in the pension account statement, each individual worker's fees paid to his/her AFORE.

- $\quad$ The authorities should examine the possibility of continuing transferring to PROCESAR - the entity in charge of processing pension collections, transfers, and withdrawals - functions currently performed by AFOREs that are subject to economies of scale (e.g., back-office accounts management), in order to further reduce costs and fees.

- $\quad$ To avoid conflict of interest, PROCESAR should not be owned by AFOREs.

- $\quad$ Legal reform would also be needed to give CONSAR regulatory authority over the main operational processes of the pension system.

40. The growth of pension funds in Mexico is outstripping the availability of suitable local assets resulting in a high exposure to the housing sector. Exposure of pension funds (including those administered by INFONAVIT) to the housing sector exceeded 40 percent of assets, if one considers the debt issued by mortgage Sofoles. The currently limited availability of eligible local assets suggests the need to allow greater portfolio diversification including in international markets. 


\section{Insurance sector}

\section{Regulations for the insurance industry have been strengthened in line with} the 2001 FSAP recommendations. Legal amendments in 2002 led to several improvements including harmonizing licensing rules for life and nonlife insurance companies and making them applicable to changes in control; and strengthening standards for corporate governance and internal controls (e.g., on the role of the Board, conflict of interest, establishing the compliance officer, and requiring independent directors). However, CNSF has not yet achieved full political, budgetary, and operational autonomy.

\section{Solvency regulation has evolved to include projections of liabilities to better} assess the adequacy of reserves. Specifically, the CNSF has completed and implemented a dynamic solvency model, an important step toward the adoption of statutory solvency rules envisioned within the Solvency II's framework. The model uses historical data to construct claim distributions for different lines of business. It allows the CNSF to calculate the probability of capital shortages of each insurance company by stressing variables that affect its underwriting and overall profit. The output of this exercise guides insurance supervisors in their work with the industry to monitor the solvency of the institutions and the adequacy of capital requirements and technical reserves. According to stress tests conducted in the context of the FSAP update, the insurance sector appears resilient to severe shocks (Appendix III).

\section{Annuities}

43. The annuities industry has stalled and measures are needed to ensure that it remains solvent. The 1997 pension reform introduced the option of purchasing private annuities with IMSS's disability, death, and workers' compensation benefits. Indeed, during 1997-2001 the annuity market grew rapidly (Figure 8). However, because disability payments under the pre-1997 regime come from the government budget (and not IMSS reserves), IMSS took advantage of legislation introduced in 2001 that allows it to issue disability benefits under the old regime, and this led to a collapse of the annuities market. The authorities should consider introducing legislation to close the unintended loophole. In addition, the National Council of Populations' mortality table that annuity companies are required to use, consists of preliminary data that should be made more accurate. 
Figure 8. Mexico: Number of New Annuitants

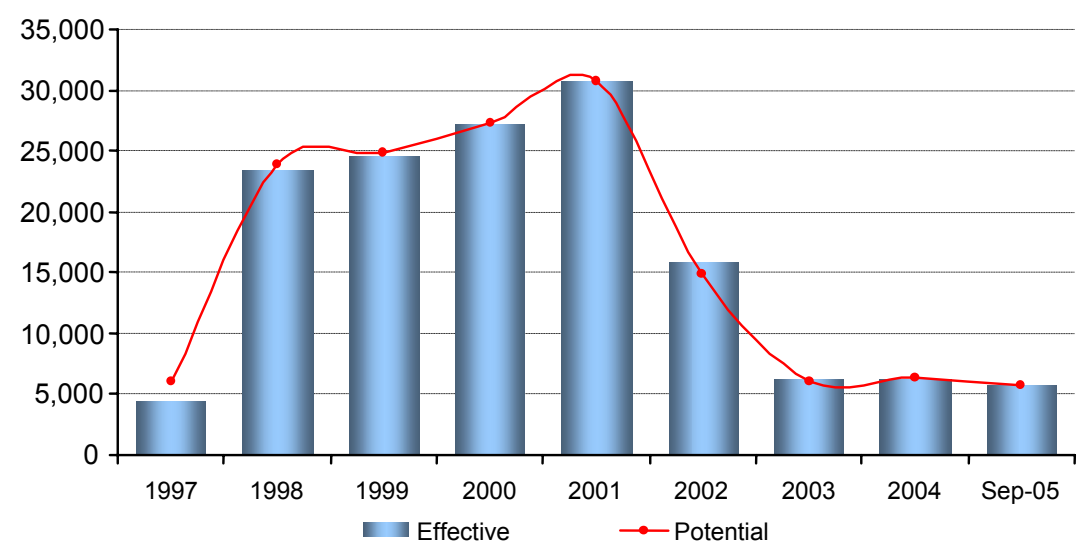

III. FinANCIAL SECTOR SUPERVISION AND REgUlation

\section{A. Banking}

44. Since 2001, a significant internal reorganization has been implemented at the CNBV. The most significant changes include: the allocation by the CNBV of considerable resources to attract, train, and retain qualified examiners; the establishment of a quality control structure to ensure standardization by examiners; a standardized "On/Offsite Examination Manual" utilizing both international best practices and locally developed best practices; and the introduction of electronic data storage to automate the rating system. However, although the operational autonomy of the CNBV has been significantly expanded, statutory political and budgetary autonomy are still lacking.

\section{Regulations have been issued to ensure transparency in financial disclosure by} financial institutions and a standardized format for regulatory reporting. In particular, the CNBV issued regulatory accounting standards in line with international standards for all banks to be applied on a consolidated basis; regulations aimed at enhancing the disclosure of information by banking institutions and financial groups; and regulations related to external auditors. The definition of "independence" of external auditors was updated and revised.

\section{However, consolidated supervision of financial conglomerates requires}

strengthening. There are factors that work to prevent the double gearing of capital such as the coordinated supervisory visits by the different regulatory agencies, and the fact that the legal entity structure of financial intermediaries calls for the computation of capital on an intermediary-by-intermediary basis. Permissible investments in other financial intermediaries must be deducted from regulatory capital. However, the lack of full-fledged consolidated supervision complicates early detection of group-wide risks. Interagency coordination could be further boosted via strong MOUs between agencies.

47. Outsourcing operations by banks have become an issue of concern. In spite of the outsourcing of many of banks' activities to jurisdictions outside of Mexico, there are no 
formal regulations on the matter. The CNBV is engaged in the design of a new outsourcing and off shoring activities regulation. ${ }^{13}$

48. Although considerable progress has been made in leveling the playing field and reducing regulatory arbitrage, there are still certain regulatory inconsistencies which require attention. In some cases, different norms apply to similar financial products. For instance, in the case of derivatives, banks can offer, negotiate, and invest in these instruments on and off exchange, but mutual funds are excluded from this market. ${ }^{14}$ There are insurance products with a savings component which are regulated differently than savings products issued by banks; and there are mutual fund-like products offered by insurance companies that do not seem to follow the segregation rules applicable to mutual funds.

49. The system of cross opinions on regulations issued by the different regulators reflects an intention to establish adequate checks and balances. Nonetheless opinions are not binding on the requesting agency and, in some cases, there are no time limits to issue opinions. To foster transparency and accountability, the requesting authority should explain its rationale when acting against the opinion received. Deadlines to issue opinions should also be established.

50. The high degree of globalization of the Mexican financial system puts a premium on cross-border cooperation among financial regulators and supervisors. Implementing effective group-wide cross-border consolidated supervision enhancing cross-border supervisory cooperation, and readying for an efficient resolution process in the case of failure of a foreign-owned financial group are all critical to the success of the Mexican regulatory and supervisory agencies in discharging their duties. The effectiveness of formal Memoranda of Understanding (MOUs) with foreign regulators must be cemented in practice by continuously enhancing the strong working relationships that already exists between Mexican supervisors and their foreign counterparts. ${ }^{15}$

\section{B. Securities Markets}

51. The quality of the regulatory and supervisory framework, and of its enforcement, has improved significantly since the 2001 FSAP. Highlights include: an expansion in the responsibility of the CNBV to license, oversee, and regulate capital markets; a clarification of the CNBV's responsibility and powers to investigate violations of the securities laws, take disciplinary action, and share information with other regulatory entities

\footnotetext{
${ }^{13}$ Despite the lack of formal regulations, in recent years the CNBV has made efforts to increase oversight over outsourcing activities.

${ }^{14}$ AFOREs are allowed to buy and sell both OTC and exchange-traded derivatives, while insurance companies have access to exchange-traded derivatives only.

15 The CNBV has signed MOUs with the Board of Governors of the Federal Reserve System, the Office of the Comptroller of the Currency, the New York State Banking Department, the Office of the Superintendent of Financial Institutions of Canada, the UK's Financial Services Authority and the Bank of Spain, among others. The effectiveness of these agreements is demonstrated on a daily basis by cross-border inspection visits as well as requests of specific information.
} 
in Mexico and internationally: ${ }^{16}$ improvements in CNBV internal operations, including an updated codification of the secondary regulations on disclosure requirements for listed companies; stronger requirements to promote the independence of external auditors; and greater transparency in the development of regulations.

52. In addition, recent legal and regulatory changes have significantly improved corporate governance practices and the protection of minority shareholder interests. The 2005 New Securities Market Law lists the fiduciary duties of a corporation's Board of Directors to shareholders and identifies prohibited activities that violate these obligations. Tender offers are now strictly regulated to protect minority interests and violators are now subject to civil and criminal liability.

53. Regulatory transparency in corporate disclosure could be enhanced. The CNBV should continue to provide informal technical assistance on compliance with its regulations - to issuers, their lawyers and accountants - and to increase the resources it devotes to reviewing financial statements and corporate disclosure of accounting issues.

54. The CNBV should consider how best to monitor the OTC market for corporate securities, should the new investment promotion vehicles (SAPIs) aimed at facilitating the listing on the stock market for small-and medium-sized enterprises develop as expected. The 2005 New Securities Market Law created two new corporate entities (SAPI and SAPI B) to facilitate the ability of small- and medium-sized companies to access private venture capital and to transition into publicly listed companies. If this approach is successful an OTC market would develop for these securities. The CNBV has the authority to develop secondary regulations pertaining to the SAPI and the SAPI B.

55. Further reforms are needed to address specific outstanding issues. First, the OTC market for thinly traded debt securities is illiquid and lacks transparency. Market efficiency would benefit from mandatory timely reporting and public disclosure of all debt transactions. Second, although the Mexican Institute of Public Accountants (IMCP) has updated Mexican accounting standards to the level of International Accounting Standards (IAS), the IMCP should maintain its work to continously review and upgrade Mexican auditing standards in line with International Standards on Audit (ISA). Finally, mutual funds and pension plan managers rely heavily upon the two independent price vendors for valuation of assets and calculation of net asset value: the functioning of price vendors should be carefully examined, including the methodologies they use and the frequency with which they adjust asset market prices.

\footnotetext{
${ }^{16}$ The CNBV has already utilized its expanded investigative powers to bring a greater number of enforcement actions. At the conclusion of an enforcement action, after payment of the fine or expiration of any legal challenges, the CNBV publishes on its website the name of the sanctioned person or company, the amount of the fine or penalty, and the provision of the law that was violated.
} 


\section{INFRASTRUCTURE}

\section{A. Payments}

\section{Large value payments}

56. The 2001 FSAP found a series of shortcomings in the large value payments systems. Specifically, there were no clear rules to prevent troubled institutions from accessing the BOM's liquidity support; the BOM was exposed to credit risk; the legal basis for clearing and settlement needed strengthening; and the scope of the oversight responsibilities of the BOM needed clarification.

57. In response, a number of reforms were adopted. By 2005, a modern hybrid payment system, Sistema de Pagos Electrónicos Interbancarios (SPEI), replaced the old system. In the SPEI, neither the BOM nor the bank participants extend credit lines. Liquidity must be managed by fund transfers between the SPEI and the Sistema de Atención de Cuentahabientes (SIAC). The payments settled are final and irrevocable. An explicit regulation of finality and the use of electronic transfers and electronic data in courts was introduced. Also, the credit lines in the old securities settlement system were eliminated, and the settlement is no longer guaranteed by the BOM. The scope of the oversight responsibilities of the BOM was clarified: it has now explicit powers to oversee all payment and securities settlement systems, including the CCPs, and has been given effective compliance instruments.

58. These changes have eliminated most of BOM's risk exposures from explicit guarantees and inadequately collateralized credit lines. The new credit facilities enable the BOM to immediately liquidate the collateral in case of a default. ${ }^{17}$

59. The intraday repo facility is the core of the liquidity management. It enables participant banks to obtain intraday loans against eligible collateral. Specifically, banks can use their federal government or IPAB bonds and the BOM's paper portfolio, as well as the DRM (Depósito de Regulación Monetaria) they have posted with the BOM.

\section{Retail payments}

60. In retail payments markets, open access to the interchange and processing infrastructures stimulate competition. However, in more concentrated financial systems such as Mexico's, instead of competing on fees and services, large banks (as owners and main users of the key retail payments networks) have an incentive to limit outsiders' access to electronic fund transfers (EFT), payroll or direct debits to outsiders, through their exclusive network, resulting in potentially higher financial services' costs and fees.

\footnotetext{
${ }^{17}$ Only banks have access to the BOM's credit lines. The eligible collateral for these credit lines are cash deposits (Depósitos de Regulación Monetaria) that banks have posted with the BOM.
} 
61. In response, the BOM has focused on promoting greater competition in retail payments. Measures have included: publishing fees and commissions charged by individual banks; fostering the use of the common interbank infrastructures by setting standards for EFTs (including tertiary information); abolishing the interchange fee for EFTs and allowing clients to fulfill credit card or interest payment obligations via an EFT from an account with another bank; abolishing limits on access to switch services for non banking institutions; and enhancing consultations with banks on the methodology to set interchange fees for debit and credit card transactions and noting the possibility of regulatory action to foster greater competition.

62. The authorities could consider further measures to foster a better balance between competition and cooperation among financial entities. These measures would aim at:

- $\quad$ Enhancing the role of nonbank service providers, such as department stores;

- $\quad$ Educating employees about their electronic payroll disbursement choices;

- $\quad$ Eliminating barriers to the provision of services using common platforms, such as direct debits and payroll via CECOBAN;

- $\quad$ Fostering the adoption of CHIP-NIP technology to promote the use of debit cards in point-of-service (POS) terminals;

- $\quad$ Changing the law to give EFTs the status of legal tender and coordinating with the SHCP the substitution of checks with EFTs for payments of social benefits, pensions, and wages; and

- $\quad$ Promoting public trust in the use of electronic payments through education and consumer protection programs.

\section{B. Anti-Money Laundering and Combating the Financing of Terrorism (AML/CFT)}

63. Initiatives were taken in response to the 2003-04 AML/CFT assessment.

Gateways and clear procedures were instituted to allow judicial authorities to obtain financial information directly from financial institutions, and to allow law enforcement to do the same on the basis of a court order during the investigation and prosecution of cases involving money laundering and terrorism financing. Also, in December 2005, the Senate approved a draft law to penalize international terrorism and terrorism financing and sent it on to the Chamber of Deputies. Two Commissions of the Chamber of Deputies are currently discussing the draft and approval is expected later in 2006. With regard to timing, the next evaluation of Mexico using the 2004 methodology, if approved by FATF, could be conducted in 2008.

\section{Banking Safety Net Arrangements}

64. Significant reforms to the banking safety net introduced since 2001 include the revamping of the prompt corrective action (PCA) regime. A legal reform in June 2004 
introduced a modern system of early warnings and PCAs. The new system imposes (cumulative) restrictions of increasing rigor on the operations of a bank in step with the deterioration of its capital ratio below a certain threshold. ${ }^{18}$ It requires CNBV to enforce, and the banks to comply with, a minimum set of corrective actions, including a regularization plan, as well as other measures deemed necessary by CNBV. This new system significantly curtails the margin for regulatory forbearance, thereby contributing to market discipline.

65. As a further refinement, the prompt correction triggers could be broadened. The current PCAs are exclusively based on capital adequacy parameters. Triggers related to other factors that might also lead to bank instability, such as chronic inadequate liquidity and unsound management could also be considered.

66. An additional and major step forward was the introduction in April 2006 of a new legal framework for bank resolution. The new law includes cessation of payments as a trigger for bank resolution. It provides for information exchange between relevant agencies. It establishes flexible options for closed-bank resolution-insured deposit transfers, purchase and assumption (P\&A) and bridge banks - subject to the least cost criteria. It improves legal protection for supervisors discharging their duties in good faith. And it allows open-bank resolution in the case of a bank considered too-big-to-fail by a Financial Stability Committee (FSC) that is composed of high level officials from the SHCP, BOM, CNBV, and IPAB.

67. Some elements of the new bank resolution framework merit close monitoring, namely the conditioned capital restoration plan and the "haircut" in too-big-to-fail cases. Under the new regime, a bank can establish a corrective action plan with the regulator by pledging 75 percent of its shares to IPAB.$^{19}$ Banks need to amend their by-laws to enter this pledge. However, there is a risk that banks might enter a preemptive judicial injunction to avoid amending their by-laws, arguing that they are experiencing no capital deficiencies, thereby making the law ineffective. The FSC must decide in too-big-to-fail cases, on a "haircut" to all uninsured liabilities without jeopardizing the financial stability of the failed bank's nondepositor creditors or the functioning of the payments system. Thus, the design of the haircut can be complex and may add pressure on the FSC.

68. The deposit insurance agency, IPAB, has not been able to build a deposit insurance fund. IPAB is still saddled with a weak balance sheet, as it must service the debt (now at 8 percent of GDP) associated with the 1994 bank bail out - and this uses 75 percent of deposit insurance premiums. As a result, IPAB has not been able to build a fund and will not be able to do so in the near future.

69. The relatively high premiums charged by IPAB provide incentives for banks to register liabilities off balance sheet. Premiums are currently set at a minimum of

\footnotetext{
${ }^{18}$ PCAs begin at an early stage, once a bank falls below the 10 percent capital ratio, somewhat before it reaches the required minimum of 8 percent.

${ }^{19}$ When a bank fails to comply with a corrective plan, IPAB would write down shareholders' shares against identified losses, become the owner of the bank and, choose the best bank resolution option under the least-cost criterion.
} 
0.4 percent of total bank liabilities (rather than of deposits). This is roughly equivalent to 0.6 percent of total deposits, rather high by international comparison.

\section{To further strengthen the banking safety net, the authorities might consider:}

- $\quad$ Ensuring that all banks amend their by-laws as soon as possible (as per PCAs);

- $\quad$ Drafting guiding principles for the FSC's mandate;

- $\quad$ Finalizing the new bankruptcy law for banks; ${ }^{20}$

- $\quad$ Transferring IPAB's debt to the federal government;

- $\quad$ Reducing the maximum insured deposit amount which, at about US\$120,000.00 is one of the highest in the world; and

- $\quad$ Changing the premium base from total liabilities to total deposits.

\footnotetext{
${ }^{20}$ These complementary reforms are necessary to, in particular, enable partial deposit transfers under P\&As. Under the recently introduced bank resolution framework, P\&As can only involve the whole amount of deposits and, hence, partial transfers are nor permitted.
} 
Table 1. Mexico: Selected Economic Indicators, 1998-2006

\begin{tabular}{|c|c|c|c|c|c|c|c|c|c|}
\hline & 1998 & 1999 & 2000 & 2001 & 2002 & 2003 & 2004 & 2005 & $\frac{\text { Proj. }}{2006}$ \\
\hline & \multicolumn{9}{|c|}{ (Annual percentage change, unless otherwise indicated) } \\
\hline \multicolumn{10}{|l|}{ National accounts in constant prices } \\
\hline Real GDP & 5.0 & 3.8 & 6.6 & 0.0 & 0.8 & 1.4 & 4.2 & 3.0 & 4.0 \\
\hline Net exports (contribution) & -1.1 & -0.5 & -1.8 & -0.7 & 0.0 & 0.7 & -0.3 & -0.9 & -0.2 \\
\hline Total domestic demand & 6.2 & 4.3 & 8.3 & 0.7 & 0.8 & 0.8 & 4.4 & 3.8 & 4.1 \\
\hline Private consumption & 5.4 & 4.3 & 8.2 & 2.5 & 1.6 & 2.3 & 4.1 & 5.4 & 4.2 \\
\hline Public consumption & 2.3 & 4.7 & 2.4 & -2.0 & -0.3 & 0.8 & -0.4 & 0.5 & 0.3 \\
\hline Gross fixed private investment & 13.8 & 7.2 & 9.0 & -5.9 & -4.1 & -1.5 & 8.8 & 9.6 & 7.0 \\
\hline Gross fixed public investment & -7.5 & 10.7 & 25.2 & -4.2 & 17.0 & 8.5 & 2.5 & -0.5 & 1.9 \\
\hline Change in business inventories (contribution) & 0.4 & -0.6 & 0.3 & 0.4 & -0.2 & -1.0 & 0.2 & -1.5 & -0.1 \\
\hline \multicolumn{10}{|l|}{ External sector } \\
\hline Exports, f.o.b. 1/ & 1.2 & 14.6 & 21.5 & -3.1 & 0.6 & 3.9 & 13.8 & 15.2 & 18.9 \\
\hline Export volume 1/ & 12.6 & 6.6 & 10.2 & 0.1 & -2.0 & -2.3 & 5.0 & 9.3 & 9.4 \\
\hline Imports, f.o.b. 1/ & 12.7 & 10.6 & 23.1 & -1.7 & -1.3 & 1.9 & 15.8 & 13.2 & 15.4 \\
\hline Import volume $1 /$ & 13.5 & 11.6 & 19.6 & -2.5 & -0.6 & -0.4 & 9.9 & 7.9 & 10.2 \\
\hline Petroleum exports (percent of total exports) & 9.7 & 11.6 & 15.5 & 13.0 & 14.6 & 17.6 & 19.7 & 23.0 & 25.8 \\
\hline Terms of trade (deterioration -) & -9.5 & 8.5 & 7.1 & -3.9 & 3.3 & 3.9 & 2.9 & 0.5 & 3.9 \\
\hline \multicolumn{10}{|l|}{ Exchange rates } \\
\hline \multicolumn{10}{|l|}{ Nominal exchange rate (US\$/Mex\$) } \\
\hline \multicolumn{10}{|l|}{ Real effective exchange rate (CPI based) } \\
\hline (average, depreciation -) & 0.8 & 8.5 & 8.3 & 6.4 & 0.0 & -10.5 & -3.8 & 4.1 & $\ldots$ \\
\hline \multicolumn{10}{|l|}{ Employment and inflation } \\
\hline Consumer prices (end of year) & 18.6 & 12.3 & 9.0 & 4.4 & 5.7 & 4.0 & 5.2 & 3.3 & 3.3 \\
\hline Formal sector employment (annual average) & 3.7 & 5.7 & 5.9 & -0.5 & -0.8 & -0.5 & 1.3 & 3.1 & $\ldots$ \\
\hline Formal sector unemployment rate (annual average) & 3.2 & 2.5 & 2.2 & 2.4 & 2.7 & 3.2 & 3.7 & 3.6 & 3.5 \\
\hline Real manufacturing wages (annual average) & 2.8 & 1.5 & 6.0 & 6.7 & 1.9 & 1.4 & 0.3 & -0.1 & $\cdots$ \\
\hline \multicolumn{10}{|l|}{ Money and credit } \\
\hline Broad money (M4a) & 25.0 & 19.7 & 12.9 & 16.0 & 10.8 & 13.5 & 12.6 & 15.2 & 12.4 \\
\hline \multirow[t]{2}{*}{ Treasury bill rate (28-day cetes, in percent, annual average) } & 24.6 & 21.4 & 15.3 & 11.2 & 7.1 & 6.2 & 6.8 & 9.2 & 7.1 \\
\hline & \multicolumn{9}{|c|}{ (In percent of GDP) } \\
\hline \multicolumn{10}{|l|}{ Nonfinancial public sector } \\
\hline Augmented balance & -6.3 & -6.3 & -3.7 & -3.7 & -3.4 & -3.2 & -2.0 & -1.4 & -1.6 \\
\hline Non-oil augmented balance & $\ldots$ & $\ldots$ & $\ldots$ & -7.8 & -7.4 & -7.8 & -7.4 & -7.2 & -7.9 \\
\hline Augmented primary balance & 0.6 & 1.3 & 1.3 & 1.0 & 0.3 & 0.3 & 1.3 & 1.8 & 2.1 \\
\hline Traditional balance & -1.2 & -1.2 & -1.1 & -0.7 & -1.2 & -0.7 & -0.3 & -0.1 & 0.2 \\
\hline Gross public sector debt & 52.6 & 55.8 & 49.3 & 47.9 & 49.7 & 50.0 & 46.0 & 44.0 & 42.8 \\
\hline Net public sector debt & 45.0 & 46.8 & 42.2 & 41.7 & 43.6 & 44.0 & 40.9 & 38.9 & 38.1 \\
\hline $\mathrm{o} / \mathrm{w}$ percent in foreign currency & 52.1 & 46.9 & 37.9 & 34.2 & 37.0 & 39.1 & 38.8 & 34.8 & 32.3 \\
\hline \multicolumn{10}{|l|}{ Savings and investment } \\
\hline Gross domestic investment & 24.3 & 23.5 & 23.7 & 20.9 & 20.6 & 20.6 & 22.1 & 21.8 & 22.0 \\
\hline Public investment & 2.8 & 3.0 & 3.6 & 3.6 & 4.2 & 4.5 & 4.6 & 4.3 & 4.2 \\
\hline Private investment & 18.1 & 18.2 & 17.8 & 16.4 & 15.0 & 14.4 & 15.0 & 15.0 & 15.5 \\
\hline Change in inventories & 3.4 & 2.3 & 2.3 & 0.9 & 1.4 & 1.6 & 2.5 & 2.5 & 2.4 \\
\hline Gross national saving & 20.5 & 20.6 & 20.5 & 18.0 & 18.6 & 19.2 & 21.1 & 21.2 & 21.9 \\
\hline Public saving 2/ & -3.5 & -3.3 & -0.1 & -0.1 & 0.8 & 1.4 & 2.7 & 2.9 & 2.6 \\
\hline Private saving & 24.1 & 23.9 & 20.6 & 18.2 & 17.7 & 17.8 & 18.4 & 18.3 & 19.3 \\
\hline External current account balance & -3.8 & -2.9 & -3.2 & -2.8 & -2.1 & -1.4 & -1.0 & -0.6 & -0.1 \\
\hline Non-oil external current account balance & -4.5 & -4.0 & -4.7 & -3.8 & -3.3 & -3.0 & -2.8 & -2.7 & -2.7 \\
\hline \multirow[t]{2}{*}{ Net foreign direct investment } & 2.9 & 2.8 & 3.0 & 3.7 & 2.7 & 2.0 & 2.1 & 1.5 & 1.6 \\
\hline & \multicolumn{9}{|c|}{ (In percent of exports of goods, nonfactor services, and transfers) } \\
\hline \multirow[t]{2}{*}{ Public external debt service 3 / } & 28.1 & 28.6 & 32.2 & 25.1 & 20.6 & 20.4 & 16.6 & 13.6 & 14.5 \\
\hline & \multicolumn{9}{|c|}{ (In billions of U.S. dollars, unless otherwise indicated) } \\
\hline Net international reserves & 30.1 & 30.7 & 33.6 & 40.9 & 48.0 & 57.4 & 61.5 & 68.7 & 70.2 \\
\hline Gross official reserves in percent of short-term debt 4 / & 65.2 & 49.9 & 65.8 & 91.6 & 110.1 & 138.0 & 161.5 & 155.4 & 157.2 \\
\hline Gross external debt (in percent of GDP, end of period) & 39.6 & 37.4 & 28.7 & 26.4 & 25.0 & 25.4 & 24.3 & 22.5 & 21.0 \\
\hline Crude oil export price, Mexican mix (US\$/bbl) & 10.2 & 15.7 & 24.6 & 18.6 & 21.5 & 24.7 & 31.0 & 42.7 & 54.4 \\
\hline
\end{tabular}

Sources: National Institute of Statistics and Geography; Bank of Mexico; Secretariat of Finance and Public Credit; and Fund staff estimates.

1/ Total exports are defined net of imports by the maquila sector. Correspondingly, total imports do not include maquila sector imports.

2/ Estimated as as the difference between the augmented fiscal balance, as reported by SHCP, and public investment, as reported in the national accounts.

3/ Includes the IMF and public development banks and trust funds net of the collateral of Brady bonds.

4 / In percent of short-term debt by residual maturity. Historical data include all prepayments. 
Table 2. Mexico: Financial Soundness Indicators for Commercial Banks, 2000-06 (In percent)

\begin{tabular}{|c|c|c|c|c|c|c|c|}
\hline & 2000 & 2001 & 2002 & 2003 & 2004 & 2005 & $1 \mathrm{Q} 06$ \\
\hline \multicolumn{8}{|l|}{ Core FSIs for Deposit-Takers } \\
\hline Regulatory capital to risk-weighted assets $1 /$ & 13.22 & 13.90 & 15.49 & 14.18 & 14.07 & 14.32 & 16.00 \\
\hline Regulatory Tier 1 capital to risk-weighted assets $1 /$ & 11.13 & 11.74 & 13.64 & 12.74 & 12.76 & 13.42 & 15.20 \\
\hline Nonperforming loans net of provisions to capital 1 / & -5.89 & -7.52 & -9.16 & -9.84 & -11.69 & -10.50 & -10.56 \\
\hline Nonperforming loans to total gross loans $1 /$ & 5.80 & 5.14 & 4.56 & 3.15 & 2.52 & 1.82 & 1.67 \\
\hline Sectoral distribution of loans to total loans $1 /$ & \multicolumn{7}{|c|}{ Non available } \\
\hline Return on assets (before e.i. \& taxes) 2/ & 0.94 & 1.20 & 1.08 & 2.16 & 2.28 & 3.31 & 3.43 \\
\hline Return on equity (before e.i. \& taxes) 2/ & 9.85 & 12.42 & 10.47 & 18.46 & 19.77 & 27.53 & 28.07 \\
\hline Interest margin to gross income $2 /$ & 65.97 & 59.48 & 58.45 & 52.60 & 60.50 & 60.77 & 59.92 \\
\hline Noninterest expenses to gross income $2 /$ & 77.31 & 71.43 & 73.22 & 64.78 & 65.64 & 57.97 & 56.89 \\
\hline Liquid assets to total assets $1 /$ & 23.30 & 30.19 & 26.39 & 31.57 & 35.08 & 33.53 & 30.62 \\
\hline Liquid assets to short-term liabilities $1 /$ & 90.98 & 97.85 & 76.20 & 88.21 & 101.90 & 89.86 & 85.74 \\
\hline Net open position in foreign exchange to capital & \multicolumn{7}{|c|}{ Non available } \\
\hline \multicolumn{8}{|l|}{ Encouraged FSIs for Deposit-Takers } \\
\hline Capital to assets $1 /$ & 9.56 & 9.42 & 11.35 & 11.44 & 11.21 & 12.55 & 12.49 \\
\hline Large exposures to capital & \multicolumn{7}{|c|}{ Non available } \\
\hline Geographical distribution of loans to total loans 1 / & \multicolumn{7}{|c|}{ Non available } \\
\hline Gross asset position in financial deriv. to capital 1/ & 3.39 & 6.85 & 5.36 & 7.74 & 18.54 & 26.86 & 27.80 \\
\hline Gross liability position in financial deriv. to capital $1 /$ & 2.03 & 9.48 & 11.67 & 22.26 & 30.56 & 40.01 & 40.38 \\
\hline Trading income to total income $2 /$ & 5.02 & 10.29 & 6.71 & 11.61 & 3.58 & 6.63 & 7.91 \\
\hline Personnel expenses to noninterest expenses 2/ & 88.01 & 81.92 & 85.07 & 88.03 & 87.48 & 86.03 & 85.01 \\
\hline Spread between reference lending and deposit rates & \multicolumn{7}{|c|}{ Non available } \\
\hline Spread between highest and lowest interbank rates & \multicolumn{7}{|c|}{ Non available } \\
\hline Customer deposits to total (noninterbank) loans $1 /$ & 73.77 & 97.00 & 98.85 & 116.99 & 119.07 & 120.10 & 114.07 \\
\hline Foreign-currency-denominated loans to total loans & 20.33 & 18.68 & 17.65 & 15.79 & 12.64 & 9.71 & 9.14 \\
\hline Foreign-currency-denom. liabilities to total liabilities & \multicolumn{7}{|c|}{ Non available } \\
\hline Net open position in equities to capital $1 /$ & 22.98 & 15.13 & 7.42 & 2.81 & 4.17 & 1.97 & 2.48 \\
\hline
\end{tabular}

1/ FSI compiled based on stock data as of the date of reference.

2/ FSI compiled based on annual flow data and annual average of end-of-month stock data.

Note: In Mexico, deposit-takers consist of commercial banks (domestically controlled and foreign controlled) and development banks domestically incorporated (resident). Financial Soundness Indicators (FSIs) compiled for Mexico cover transactions conducted by all resident deposit-takers within the country as well as through their branches abroad. Resident deposit-takers have no deposit-taking subsidiaries abroad. Activities conducted by nondeposit-taking subsidiaries of resident deposit-takers are not included in the FSIs for deposit-takers. 
Table 3. Mexico: Regional Comparison of Equivalent Fees Over Assets, 2005

\begin{tabular}{lccc}
\hline & 1 year & 25 years & 40 years \\
\hline & & & \\
Argentina & 2.89 & 1.62 & 0.92 \\
Bolivia & 1.35 & 0.56 & 0.42 \\
Chile & 3.81 & 1.08 & 0.62 \\
Colombia & 3.47 & 0.91 & 0.52 \\
Costa Rica & 0.74 & 0.99 & 0.89 \\
El Salvador & 3.09 & 1.44 & 0.91 \\
Mexico & 3.19 & 0.86 & 0.49 \\
Peru & 4.59 & 1.19 & 0.78 \\
Dominican Republic & 1.47 & 1.00 & 0.57 \\
Uruguay & 4.31 & 0.93 & 0.53 \\
\hline
\end{tabular}

Source: CONSAR. 
ObServance of Financial Sector Standards AND CODES-Summary ASSESSMents

This annex contains summary reassessments of two international standards and codes relevant for the financial sector. The assessments have helped to identify the extent to which the supervisory and regulatory framework is adequate to address the potential risks in the financial system. The following detailed assessments of financial sector standards were undertaken.

- The Basel Core Principles for Effective Banking Supervision (BCP), by Rudolph Zepeda (Directing Bank Examiner, U.S. Federal Reserve Bank of Atlanta);

- The IOSCO Objectives and Principles of Securities Regulation by Jonathan Katz (securities expert, formerly with the U.S. Securities and Exchange Commission);

The reassessments relied on several sources including:

- Self-assessments by the supervisory authorities;

- Reviews of the relevant legislation, regulations, policy statements, and other documentation;

- Detailed interviews with the supervisory authorities;

- Meetings with the SHCP, BOM, CNBV, CNSF, CONSAR, and other authorities; and

- Meetings with financial sector firms and associations, and academics. 


\section{Basel Core Principles for EfFective Banking SuPERVision}

\section{General}

71. Oversight of the financial system is administered by multiple regulators. The SHCP sets regulatory policy for the financial system. CNBV is the primary banking regulator. BOM also has regulatory responsibilities. The institutional framework also includes the Stock Exchange (Bolsa) and IPAB.

\section{Main findings}

72. The banking system has significantly improved its compliance with the 25 BCPs. The 2001 FSAP noted a number of supervisory and regulatory shortcomings. In particular, the autonomy of the CNBV needed to be strengthened; the definition of capital did not reflect the bank's economic capital; there was a need to achieve consistency in the treatment of information, decision making, and enforcement within the CNBV; and there was a need for greater contribution from the Boards of Directors and external auditors, coupled with appropriate accountability. As indicated below, most of the observed shortcomings have now been addressed.

\section{Preconditions for effective banking supervision (BCP 1)}

73. The current legislation parcels out oversight functions among three regulators: the SHCP, the BOM, and the CNBV. The SCHP has started to transfer gradually some of its regulatory powers to the CNBV. In particular, the new Securities Market Law-LMV (December 2005) transfers the granting of licenses for securities intermediaries to the CNBV. Planned amendments to the Law of Credit Institutions (LIC) would do the same for bank licenses. Although a protocol for the sharing of information and joint examinations has not been formalized, cooperation between agencies has been highly effective. The CNBV shares information with other regulatory bodies and performs joint inspections with other agencies regularly.

\section{Licensing and structure (BCPs 2-5)}

74. SHCP grants bank licenses. If planned reforms to the LIC go through, the licensing of banks and securities intermediaries would reside at the CNBV. Currently, changes in ownership or controlling interests for existing banks must be approved by the SHCP. Although the CNBV renders de facto binding opinions on the matter. The CNBV is seeking amendments to the LIC that would grant it control over requests on ownership changes. The CNBV is also working on the reform of the LIC to have a formal authority in the process of approving investments by the banking institutions.

Prudential regulations and requirements (BCPs 6-15)

75. Mexican banks comply with Basel I' s recommended capital requirements, and are positioned to comply with Basel II recommendations regarding credit and 
operational risk. Large financial institutions (including large foreign banks) are expected to start parallel runs in 2007 in order to adopt the advanced approaches of Basel II.

76. In August 2005, a new banking regulation updated prudential oversight governing the credit process for banking institutions. The functions and responsibilities for officers involved in the credit process were clarified. The credit approval process was modified to ensure accountability by the banks' Board of Directors. The CNBV now reviews the underwriting methodology, and follows up on identified deficiencies. The CNBV can require precautionary loan-loss provisions for problem loans and may bar new credits. New provisioning rules have been issued in line with international best practices. The revamping of the credit rating and provisioning regulations in August 2004 assured that banks could apply internal credit rating (in the computation of provisions) for all types of private and sub sovereign loans. The reform also relies on credit risk mitigation techniques such as guarantees, and collateral. The CNBV now relies on more accurate classification of loans and provisioning in computing required loan-loss reserves.

77. Legislation allowing the CNBV to rule on concentration risks was modified in 2003 and limits were established on the maximum (12 percent) concentration of credit risk to either individuals or groups, as a function of basic capital (Tier 1). The new regulation allows banks to lend more than 12 percent to a particular group provided it has higher capital levels. The maximum exposure to the top three borrowers cannot exceed 100 percent of Tier 1 capital.

78. The general framework for connected lending has been significantly revised. In their monthly reports to the CNBV, banks must provide an indicator on related lending. All related lending must be approved by the bank's Board of Directors and be limited to 75 percent of Tier 1 capital.

79. The CNBV does require that banks perform an analysis of country risk and concentration. Their examiners review country risk within their bank's portfolios, however the review of risk is limited to letters of credit issued by banks for their customers. Although regulation and supervisory guidelines are very limited to country and transfer risk, the CNBV's opinion is that these risks are not material and do not deserve special attention. The exposure to letters of credit compared to their bank's capital is minimal. The CNBV has no jurisdiction over parallel banks unless a Mexican bank has some ownership interest, which may inhibit supervision on country risk.

80. The CNBV utilizes their model and information technology systems for calculating Value at Risk (VAR) in accordance with Basel guidance. Their model tests interest sensitivity and stress tests a bank's portfolio utilizing worst case scenarios based on historical data for the Mexican market. Each bank is required to perform tests with their own proprietary VAR models which are then compared to the CNBV's model to ensure that conservative assumptions and results are within an acceptable range. A banking circular sets the norms for contingency plans required of all banks that must be approved by their Board of Directors. Further improvement of the onsite examination and verification of contingency plans and their implementation is needed. These contingency plans are reviewed at each annual examination for adequacy and testing. 
81. Since 2003 the Mexican banks have been required by law to have in place a comprehensive risk management process with Board and senior management oversight. The annual bank examinations conducted by the CNBV review how each bank exercises risk management and ensures appropriate capital is assigned to the corresponding risks.

82. Regulations on internal controls and auditing were first introduced in 2001. In 2005 , these regulations were updated in accordance with international standards and extended to development banks. Key objectives include to control operational risk, reinforce comptroller and internal audit functions, develop and update information systems, and minimize conflicts of interest and clearly define the field of action for all participants. Examiners analyze at each annual examination the corporate governance function and the independence of the audit function, as well as its adequacy. The minutes of the audit committee for the Board are reviewed to ensure that the Board and senior management have informed the committee of any deficiencies. The external auditor, though hired by management, must report to both the Board and the committee in accordance with the Circular Única de Bancos updated in 2006.

\section{Methods of ongoing supervision (BCPs 16-20)}

83. The CNBV's onsite supervision has greatly improved since 2001. The onsite supervision is conducted at least annually (quarterly for larger banks). Internally the CNBV has set up a qualitative directive to review best practices regarding onsite supervision and incorporate these practices in the Supervision Manual, which is continuously updated on the CNBV's intranet for the examiners in the field. The methodology for bank examinations has been standardized. The Circular Única de Bancos requires external auditors to report to the CNBV the findings of their audits. The CNBV has the authority to review the audit and shortcomings are reported to the external audit firm's management. The CNBV also has the authority to fine or request removal of a partner for violations to either legislation or regulations.

84. Banks are required to issue monthly financial reports which are reviewed by the CNBV. Prior to issuing this report banks must meet with the CNBV officials who have validated the information. The CNBV meets at a minimum once quarterly with top-tier management to discuss any concerns and this is documented in the examiner's work papers especially in cases where deficiencies may require official sanctions. Minutes of exit meetings after an examination are taken to ensure both parties understand the findings. The CNBV is sometimes in daily contact with the larger institutions when there are significant changes in the monthly or quarterly financial reports.

\section{The offsite supervision is conducted by the CNBV and the BOM through} quarterly reports where financial information from the banks is ultimately reported. These financial reports are later validated by onsite inspections. The system utilized by both of these supervisors allows offsite supervision on a solo basis by each entity. However, large financial groups whose consolidated financial reports encompass numerous activities require close coordination with other supervisors to ensure all activities are transparent and supervised. The CNBV has the authority to fine and sanction banks, and even bank officials individually, for poor reporting of information. 
86. Validation of supervisory information is conducted by the CNBV's examination teams consisting of four to six examiners, during a two-to-three month period in accordance with the risks and size of the bank. The CNBV is also actively involved in the creation of an oversight framework for external auditors in Mexico.

87. Legislation is currently under study by the SHCP with the opinion of the CNBV to ensure full comprehensive consolidated supervision. However, although current legislation allows adequate supervision, there is a distribution of duties between several regulators. Bank licensing and supervision are under different regulators, whereas both functions are under one regulator for the securities industry and a single regulator should also be considered for the banking industry.

\section{Accounting standards (BCP 21)}

88. The CNBV developed regulatory accounting standards in accordance with international accounting standards. For instance, to prepare consolidated financial statements banks have to include all subsidiaries, regardless of whether they are financial entities. The CNBV had already issued regulation related to external auditors in 1994 and 2000 (Circulars 1222 and 1479). Modifications were issued in April 2005 as a result of changes in the best practices of international regulation (such as Sarbanes-Oxley). The definition of "independence" was updated and revised. Specific guidelines regarding requirements for independence are required of external auditors and their offices (e.g., audit partner rotation shall not be longer than five years). There are limitations to the provision of services by auditing firms (other than auditing), such as book keeping or other services related to accounting records, design and implementation of financial information systems, appraisal or valuation services, internal audit services, and some legal services.

\section{Formal powers of supervisors (BCP 22)}

89. The new Circular Única de Bancos establishes an early warning system. In addition, the CNBV provides information through its website by rating the banks' capital levels in five categories. These capital levels are in accordance with the standards set by the BOM and the regulations set forth by the SHCP. The system was tested in 2004 when a bank's capital fell below the authorized capital level due to derivatives trading. In November 2004, the CNBV issued the "Reglas de Caracter General a que se refiere el Artículo 134 Bis de la Ley de Instituciones de Crédito," which provides the framework under which PCA is undertaken.

\section{Cross-border banking (BCPs 23-25)}

90. The CNBV continues to supervise Mexican subsidiaries, agencies, and branches abroad with its ongoing review of each bank's strategic plan under the Circular Única de Bancos. Difficulty is noted in the structures set up by Mexican individuals that basically form parallel banks in other jurisdictions. Although the shareholders are the same, the bank is set up in a foreign jurisdiction where the CNBV has no authority. When the foreign financial institution is owned by a bank holding company, the CNBV has the authority to request financial information to satisfy its concerns. Currently Mexican banks are performing data- 
processing functions for foreign subsidiaries and the CNBV has the authority to review the process. However, outsourcing to entities outside of Mexico may cause problems for the CNBV in the future.

\section{The CNBV maintains a dialog with home country supervisors of all foreign}

banks represented in Mexico. The supervisors of the U.S., Canada, UK, and Spain regularly visit the CNBV annually and discuss mutual concerns. Joint examinations with foreign supervisory entities are permitted with advance notice and provided that a Memorandum of Understanding (MOU) with that foreign supervisor is in place prior to the examination.

\section{The CNBV has signed bilateral MOUs with 12 foreign bank regulatory agencies and is currently negotiating six more primarily with the authorities of Central} American countries. The 12 MOUs are mainly with supervisors of the major banking institutions with subsidiaries in Mexico. The CNBV has also signed 32 MOUs with foreign securities regulatory agencies abroad.

Table 4. Recommended Action Plan to Improve Compliance with the Basel Core Principles

\begin{tabular}{|l|l|}
\hline \multicolumn{1}{|c|}{ Reference Principle } & \multicolumn{1}{|c|}{ Recommended Action } \\
\hline $\begin{array}{l}\text { Objectives, Autonomy, Powers, and Resources } \\
\text { (BCP 1) }\end{array}$ & $\begin{array}{l}\text { Make the CNBV a single autonomous supervisory } \\
\text { agency with power to control all the activities from the } \\
\text { licensing through the demise of a financial institution } \\
\text { including all nonbank subsidiaries. }\end{array}$ \\
\hline Investment Criteria (BCP 5) & $\begin{array}{l}\text { The CNBV should have formal authority to approve } \\
\text { investments by banking institutions. Currently, the } \\
\text { CNBV shares approval authority with the SHCP. The } \\
\text { SHCP historically has followed the opinion of the } \\
\text { CNBV in these matters. }\end{array}$ \\
\hline Connected Lending (BCP 10) & $\begin{array}{l}\text { The CNBV should have the authority to make } \\
\text { discretionary judgments about the existence of } \\
\text { connections between banks and other parties, especially } \\
\text { where they have taken measures to conceal such } \\
\text { connections. Furthermore, limits to shareholders could } \\
\text { be imposed as a share of shareholder's investment rather } \\
\text { than Tier 1 capital, so as to limit exposure to the value } \\
\text { of her/his investment in the bank. }\end{array}$ \\
\hline Consolidated Supervision (BCP 20) & $\begin{array}{l}\text { The CNBV should have full power to license or revoke } \\
\text { licenses of any bank, nonbank subsidiary, or financial } \\
\text { group and demand full disclosure on a consolidated basis } \\
\text { with the concurrence of the CNBV's Board of Directors. } \\
\text { Legislation must give the CNBV the authorization to } \\
\text { approve investments or outsourcing of critical functions } \\
\text { by all banks or financial groups, and the ability to } \\
\text { examine these institutions on an enterprise-wide basis. }\end{array}$ \\
\hline
\end{tabular}


Globally Consolidated Supervision (BCP 23)

Continue to formulate legislation to allow the CNBV to supervise financial or nonfinancial institutions set up by Mexican individuals that basically form parallel banks in other jurisdictions where the CNBV has no authority. When the foreign bank is owned by a holding company, the CNBV has the authority to request financial information to satisfy its concerns. However, Mexican banks are performing data-processing functions for foreign subsidiaries, as well as outsourcing to entities outside of Mexico. The CNBV should have the supervisory authority to review these functions regardless of jurisdiction.

\section{Authorities' response}

93. The financial authorities have willingly cooperated with the World Bank and the International Monetary Fund during the progress of the 2006 Financial Sector Assessment Program carried out in Mexico. In our opinion the assessment has been carried out in a highly professional manner.

94. In connection with the assessment of compliance with the Basel Core Principles for Effective Banking Supervision, we consider that the report provides a fair appraisal of the implementation by the National Banking and Securities Commission (CNBV) of the principles.

95. We will continue our efforts to strengthen our prudential framework and to incorporate new international best practices as they may arise. However, the broad challenge ahead remains the achievement of an autonomous status for the CNBV. Although the impending reallocation of powers among financial authorities will be a significant step forward, we must maintain our efforts in bringing proposals to the legislative branch that will ensure an independent supervisor in accordance with international best practices.

\section{IOSCO ObJectives AND Principles of Securities Regulation}

\section{General}

96. This assessment is an update of the 2001 assessment of the National Banking and Securities Commission (CNBV), and other relevant regulatory agencies and self-regulatory organizations (SRO). It was prepared in accordance with the guidance contained in the IOSCO Assessment Methodology Guidelines (December 2003 version). Material contained in the 2001 IOSCO Assessment Report was used when applicable.

\section{Description of regulatory structure and practices}

\section{The securities regulatory environment}

\section{CNBV was created in $\mathbf{1 9 9 5}$ and is headed by a $\mathbf{1 0 - m e m b e r ~ B o a r d ~ o f ~ G o v e r n o r s . ~}$}

Five members, including the President of the Commission, are appointed by SHCP, three members are appointed by the $\mathrm{BOM}$, and the pension regulator (CONSAR) and the insurance 
regulator (CNSF) each appoint one member. The SHCP has broad supervisory responsibility over the CNBV, such as setting its annual budget, the final authority over legal interpretations of the relevant laws and final authority over referral of matters to the Ministry of Justice for criminal action. The SHCP has final responsibility for approval of exchange licenses, derivative firms and banks, with a duty to consult with the CNBV and the BOM. Until 2005 it had similar responsibility for licensing securities firms. The BOM has final authority over matters involving the government debt market and over matters dealing with the extension of credit.

98. COFEMER is a Mexican agency created in 2001 with advisory responsibility over governmental regulations. All CNBV regulations are subject to review by COFEMER, which has the responsibility to publish proposals in its website and oversee the public comment process. CONDUSEF is a government agency with broad authority to act as an informal ombudsman for involved in consumer disputes. It does not possess enforcement authority.

\section{Self-regulatory organizations (SROs) $)^{21}$}

99. There are several private entities that have been designated SROs under Mexican law. These include the Bolsa, the Mexican stock exchange; MexDer, the derivatives exchange; AMIB, the organization of securities firms; AMAII, the association of independent investment advisers; INDEVAL, the national securities depository and its subsidiary the $\mathrm{CCV}$, the central counterparty for equity clearance and settlement and ASIGNA, the central counterparty for clearance and settlement on MexDer.

100. The Bolsa performs limited regulatory functions. Its surveillance function is limited to staff monitoring trading activity and imposing trading halts when a stock moves more than 15 percent within a day or when there is the possibility that an issuer has not disclosed material information. It also reviews the prospectuses of all new listings in conjunction with the CNBV to ensure that listing standards are met. Because the Bolsa does not have the authority to compel testimony or disclosure of information by its members or its members' employees, it is unable to conduct investigations. Accordingly, it does not take disciplinary actions. All suspicious activities are referred to the CNBV. MexDer, which is owned by the Bolsa, performs analogous functions in the futures market.

101. AMIB conducts licensing exams for employees of securities firms, mutual funds, and bank employees who are involved in selling securities. It adopts regulations for securities firms concerning internal operations, such as compliance and risk management functions and receives and monitors member firms compliance with CNBV capital requirements. It has the authority to fine its members for failure to file or for filing incorrectly, required reports.

\footnotetext{
${ }^{21}$ In addition to the powers enjoyed by SROs, the CNBV maintains oversight of those sectors.
} 
102. AMAII is a voluntary organization. It has 25 members (out of 45 registered independent advisers) who have agreed to be inspected periodically. AMAII has retained a large accounting firm to perform eight inspections annually.

103. INDEVAL, the securities depository, performs some self-regulatory functions but has no disciplinary authority. INDEVAL owns and operates the CCV, the central counterparty for equities clearance and settlement. The CNBV audits INDEVAL and CCV regularly.

\section{Mexican legal framework for securities markets}

104. The 1934 Mexican Corporation Law (LSM) and the New 2005 Securities Market Law (LMV) form the framework for securities regulation.

105. In 2001, five limitations were identified as impeding IOSCO's core securities regulation objectives, namely: (a) the scope of the CNBV's enforcement authority, its ability to publicize its actions and thereby promote investor confidence in the securities markets and deter misconduct by others; (b) the need to promote market efficiency and reduced regulatory overhead by introducing greater flexibility in the regulatory structure; (c) the need to enhance public confidence in regulation by adopting procedures to ensure public input into the regulatory process and to enhance procedural due process in the disciplinary process; (d) the need to enhance minority shareholder rights through improved corporate governance standards and easier access to the courts to protect these rights; and (e) the difficulty in obtaining assistance from overseas regulators when pursuing investigations of possible Mexican securities law violations due to an inability to provide reciprocal assistance to foreign regulators because of Mexican bank secrecy laws.

106. In response, Congress enacted a series of legal reforms designed to address each of these limitations. The changes expanded the authority of the CNBV to conduct investigations and to publicly disclose disciplinary actions, to share information with other government regulators and with foreign regulators, to enact secondary regulations to protect minority shareholder rights and to shift from a merit-based to a disclosure-based system of securities offering review. The law also mandated changes in public listed company governance, such as creation of an audit subcommittee of a company's Board of Directors, mandatory minimum percentage of independent directors on a company Board, and specific rights of representation for minority shareholders with 10 percent holdings and the right to initiate private litigation by holders of 20 percent interests. The law governing mutual funds was also amended to require fundamental changes in the legal structure of mutual funds that were designed to expand competition and to increase fund investor protections by requiring the separation of certain operational functions.

107. Following passage of the 2001 reforms, the CNBV addressed some of the concerns over its operational transparency by updating, and comprehensively codifying many discrete secondary regulations into unified regulations. It utilized its information sharing authority to become a signatory to the IOSCO multilateral agreement on information sharing. It began publicizing basic information on completed disciplinary actions. Consistent with other newly enacted law, it began systematically soliciting public and industry input in 
the development of secondary regulations, both through informal communication and through formal publication for comment of regulatory proposals through COFEMER's website. In the area of minority shareholder rights it adopted a secondary regulation on tender offers that required price equality for different classes of securities, even those with different voting rights.

108. The new LMV, enacted in December 2005 and effective in June 2006, brought significant changes to the regulatory framework. These changes can be grouped into three categories: (a) further expansion of the CNBV's authority; (b) substantial changes in the corporate governance of publicly listed companies; and (c) creation of two new types of corporate entities, designed to facilitate the ability of small and medium-sized companies to raise capital and transition to public listed company status.

109. The new law transfers the authority to license securities firms from the SHCP to the CNBV, and the CNBV may now issue limited-function brokerage licenses. Also the CNBV will have the authority to appoint special administrators to manage failing securities firms and, if necessary, revoke a firm's license. The CNBV was given additional enforcement powers. It now has the power to investigate and sanction attorneys, auditing firms and external auditors, and corporate officers and Board members responsible for securities law violations and to refer such misconduct to the Ministry of Justice for criminal action. The new law also clarified what is prohibited regarding insider trading and manipulative activities in the derivatives market.

\section{The 2001 amendments to the LMV made fundamental changes in the} responsibilities of listed companies that were designed to increase the rights of minority investors. The boards of listed companies were required to include at least 25 percent of independent directors. An audit subcommittee of the Board was required, to be composed of a majority of independent directors and chaired by an independent director. Companies were required to have a comisario, an internal reviewer and certifier of the external audit report. Shareholders controlling 10 percent of the company stock were given the right to appoint a second comisario. At each annual general meeting, the comisario was required to deliver a report on the accuracy, adequacy, and rationality of financial and other information presented to the Board, including an opinion on whether the financial statements were prepared in accordance with Mexican accounting standards. While these persons were not required to be licensed accountants, in practice they were typically an accountant at the firm that performed the external auditor. Under Mexican law, they were subject to personal civil or criminal liability for failure to perform their duties, although enforcement seems to have been rare. Investors with 20 percent of a company stock were also authorized to bring a private lawsuit against a company for violation of Mexican law. Finally, the CNBV was given the authority to adopt a secondary regulation on tender offers.

\section{The December 2005 legal reforms further expanded the minority shareholder} protections of the 2001 law. The CNBV secondary regulation on tender offer enacted in 2003 was codified into law. Audit committees are now required to be composed of 100 percent independent directors. The law created the title of company Director General (comparable to an American CEO) and explicitly delineated the responsibilities of the CEO and the company Board. The CEO was made responsible for the company's records and 
accounting processes and the Board, through the Audit Committee, was given responsibility for review of the external audit and the duties previously assigned to the comisario. This function was eliminated for publicly listed companies. The law also created the concept of a single economic unit. The Board's responsibilities extended to any company subsidiary or affiliate that is part of a company single economic unit. The audit committee now has the power to require appearances by all company employees to discuss accounting and auditing questions, including employees of these subsidiaries.

112. The 2005 law also, for the first time, specifies that company Board members and officers have fiduciary duties to the company and its shareholders, a duty of due care and a duty of loyalty. Board members are specifically prohibited under the law from the following: (a) authorizing related party transactions without full disclosure and formal actions; (b) voting if a conflict of interest exists; and (c) using privileged information and taking advantage of company assets or corporate activities without authorization. Moreover, they must also disclose any conflicts.

113. Violation of these duties can be punished in civil litigation brought by the company or a minority shareholder owning 5 percent, a reduction from the 2001 law (although private derivative litigation in Mexico continues to be rare). A private action can be resolved through a negotiated settlement, with the explicit approval of the company Board. The CNBV can bring an action under the law to suspend or bar an officer or a director for up to five years.

114. The 2005 New Securities Market Law also created two new corporate vehicles, SAPI and SAPI B corporations. These entities are designed to make it easier for small and medium private companies to raise capital and make the transition to public listed company status.

115. A SAPI will be able to issue securities to institutional investors and qualified investors in private transactions, without having to register with the CNBV or on the National Corporate Registry. In addition to having no disclosure obligations, a SAPI will not be subject to the corporate governance and auditing requirements that apply to listed companies, and there will be no restrictions on the types of securities it may offer or special features it can attach to a security. A SAPI B will be a three-year transitional status for a SAPI interested in becoming a listed public company. During the three-year period a SAPI B will have special listing status on the Bolsa while it implements a plan to fully conform to the legal obligations of listed companies. 
Table 5. Recommended Action Plan to Improve Implementation of the IOSCO Objectives and Principles of Securities Regulation

\begin{tabular}{|c|c|}
\hline Reference Principle & Recommended Action \\
\hline $\begin{array}{l}\text { Principles Relating to the } \\
\text { Regulator } \\
\text { (P 1-5) }\end{array}$ & $\begin{array}{l}\text { Enhance CNBV's budgetary independence. SHCP control over the CNBV } \\
\text { operating budget has resulted in an annual budgets typically } 10-20 \text { percent less } \\
\text { than the regulatory fees collected. While reductions of this magnitude do not } \\
\text { appear to have measurably affected CNBV operations, the potential exists if } \\
\text { the Mexican financial system continue to grow in size. } \\
\text { The creation of fixed-term appointments for its Board members and a } \\
\text { reduction in the number of areas requiring formal consultation with other } \\
\text { governmental entities would also enhance CNBV independence and } \\
\text { effectiveness. } \\
\text { Additional transparency and due process protection in the CNBV disciplinary } \\
\text { process would be beneficial. }\end{array}$ \\
\hline $\begin{array}{l}\text { Principles of Self-Regulation } \\
\text { (P 6-7) }\end{array}$ & $\begin{array}{l}\text { The multiplicity of governmental agencies involved in the oversight of SROs } \\
\text { has impeded the futures market's ability to innovate and expand. }\end{array}$ \\
\hline $\begin{array}{l}\text { Principles for the Enforcement of } \\
\text { Securities Regulation (P 8-10) }\end{array}$ & $\begin{array}{l}\text { The CNBV should continue to develop its enforcement program and utilize the } \\
\text { enhanced powers that it has received. While the legal authority for private } \\
\text { action has been expanded this has not been a widely used adjunct to } \\
\text { governmental action. It would be beneficial if the CNBV had the legal } \\
\text { authority to issue orders requiring remedial or corrective action and possessed } \\
\text { some ability to require persons or entities to reimburse persons who suffered } \\
\text { losses from violations. While these remedies are not required under the IOSCO } \\
\text { principles, they are included within the broad list of possible sanctions that a } \\
\text { regulator could possess. Finally, the CNBV should utilize its authority to } \\
\text { publicize its activities to inform the investing public and educate regulated } \\
\text { persons about conduct that is improper. }\end{array}$ \\
\hline $\begin{array}{l}\text { Principles for Cooperation in } \\
\text { Regulation (P 11-13) }\end{array}$ & $\begin{array}{l}\text { The CNBV should continue its efforts to promote and enhance information } \\
\text { sharing among Mexican financial regulators and with foreign regulators. }\end{array}$ \\
\hline Principles for Issuers (P 14-16) & $\begin{array}{l}\text { The CNBV should continue its efforts to emphasize analysis of financial } \\
\text { statements and accounting issues in its disclosure review program. It would be } \\
\text { beneficial to enact secondary regulations to implement the SAPI and SAPI B } \\
\text { provisions of the } 2005 \text { reform law. } \\
\text { The impact of the tender offer restrictions on share price should be monitored } \\
\text { to ensure that it doesn't unintentionally become a statutory poison pill } \\
\text { preventing successful tender offers in the marketplace. } \\
\text { The CNBV should become a catalyst to assist the private sector in identifying } \\
\text { and properly training independent directors and educating them on their } \\
\text { responsibilities under the } 2005 \text { reforms. } \\
\text { The IMCP should take the next step to review and upgrade Mexican auditing } \\
\text { standards in line with International Standards on Audit (ISA). }\end{array}$ \\
\hline
\end{tabular}




\begin{tabular}{|l|l|}
\hline \multicolumn{1}{|c|}{ Reference Principle } & \multicolumn{1}{c|}{ Recommended Action } \\
\hline $\begin{array}{l}\text { Principles for Collective } \\
\text { Investment Schemes (P 17-20) }\end{array}$ & $\begin{array}{l}\text { The CNBV should continue its trend toward disclosure regulation of mutual } \\
\text { funds and also reexamine the need for its system of categorizing mutual funds } \\
\text { and restricting a fund manager's investment strategies. Secondary regulations } \\
\text { to enable mutual funds to invest in derivatives should be finalized and } \\
\text { restrictions on stock lending, short selling, and repo transactions should be } \\
\text { eliminated. } \\
\text { The reliance on price valuators makes the effectiveness of the two valuators } \\
\text { pivotal to pricing and industry integrity. Their operations should be carefully } \\
\text { reviewed to determine whether a secondary regulation is needed on alternative } \\
\text { pricing methodology and the occasions when it should be used. } \\
\text { The CNBV should complete its efforts to resolve with the insurance regulator } \\
\text { the problem of insurance companies' marketing insurance products that are } \\
\text { inaccurately described as mutual funds. }\end{array}$ \\
\hline $\begin{array}{l}\text { Principles for Market } \\
\text { Intermediaries } \\
\text { (P 21-24) }\end{array}$ & $\begin{array}{l}\text { The CNBV should complete its secondary regulation on licensing of limited } \\
\text { function securities firms. AMIB should be encouraged to develop tests for } \\
\text { certification of compliance and risk management officers at firms. The CNBV } \\
\text { should continue its efforts to monitor risk management on a consolidated } \\
\text { basis. }\end{array}$ \\
\hline $\begin{array}{l}\text { Principles for the Secondary } \\
\text { Market } \\
\text { (P 25-30) }\end{array}$ & $\begin{array}{l}\text { The futures market would benefit from a streamlined oversight system that } \\
\text { does not unduly delay its ability to develop and offer new products. } \\
\text { The goals and objectives of the Mercado Global should be examined, in } \\
\text { conjunction with the costs resulting from higher transaction costs and lost tax } \\
\text { revenue. } \\
\text { An effort should be made to improve price transparency in the debt market, by } \\
\text { expanded access to quotations and timely access to last sale reporting } \\
\text { information on thinly traded debt issues. }\end{array}$ \\
\hline
\end{tabular}

\section{Authorities' response}

116. The financial authorities have willingly cooperated with the World Bank and the International Monetary Fund during the progress of the 2006 Financial Sector Assessment Program carried out in Mexico. In our opinion the assessment has been carried out in a highly professional manner.

117. In connection with the assessment of compliance with the Objectives and Principles for Securities Regulation issued by the International Organization of Securities Commissions, we consider that the report provides an adequate evaluation of the implementation by the National Banking and Securities Commission (CNBV) of the Principles.

118. We are confident that the New Securities Market law will constitute a very sound framework upon which we will continue our efforts towards the development of the securities markets.

119. As in the case of banking, the broad challenge ahead remains the achievement of an autonomous status for the CNBV. Although a significant reallocation of powers among 
financial authorities has already taken place in the securities field, we must maintain our efforts in bringing proposals to the legislative branch that will ensure an independent supervisor in accordance with international best practices. 


\section{KeY Milestones In THE REFORM OF THE FinANCIAL SECTOR (2001-2006) ${ }^{22}$}

- Credit Institutions Law and Financial Groups Law. Aimed at channeling a greater proportion of national savings through the financial system; fostering long-term savings; strengthening banking regulation and supervision; promoting transparency and competitiveness; fostering new financial products and services; and strengthening the credit institutions' corporate governance; and broadening the range of services offered.

- $\quad$ Amendments to the Rules of Capitalization Requirements for Multiple Banking Institutions and Development Banks. Aimed at advancing the convergence between banking regulation and international standards.

- $\quad$ Amendments to the Miscellany on Credit Collateral. Aimed at promoting bank lending by reducing transaction costs; widening the options to secure credit transactions; granting greater judicial certainty to creditors and borrowers; and promoting an orderly and sustainable recovery of defaulted bank loans.

- Credit Information Institutions Law. Aimed at regulating the establishment and operation of credit information societies; and ensuring a proper access to credit information, while respecting valid privacy concerns.

- Credit Institutions Law. Established a prompt corrective regime consistent with international best practices.

- Law of Transparency and Ordering of Financial Services. Regulates commission fees, interbanking fees and other aspects related with the provision of financial services; prohibits discriminatory practices between credit institutions and between users; establishes transparency requirements in contracts and check account balances, credit and debit cards; foresees transparency mechanisms to allow clients of credit institutions to know the carried out transactions and their fees; and establishes sanctions for breaches of the law.

- $\quad$ Organic Law of the Federal Mortgage Society. Aimed at increasing the housing supply for wage earners and other workers; promoting the construction and acquisition of housing, preferably low-income; and fostering mortgage securitization and increasing credit supply for housing construction and acquisition.

- Popular Savings and Credit Law and Organic Law of the Bank of National Savings and Financial Services. Strengthened the institutional and regulatory framework of popular savings and credit activities, increasing access of low-income sectors and small enterprises to the formal financial sector; established the conditions to foster the development of a popular savings and credit system; created the Bank of National Savings and Financial Services, which offers training and consulting services to popular savings and credit entities, and promotes cost reduction through centralized provision of services subject to economies of scale.

\footnotetext{
${ }^{22}$ Sources: "Institution Building in the Financial Sector," G20, 2005; and FSAP Update team discussions with the Mexican authorities.
} 
- Organic Law of the Financiera Rural. Aimed at supporting the development of agriculture, forestry, fishing and other rural activities. The New Financiera Rural replaced the former Rural Credit Bank (BANRURAL). Financiera Rural does not take deposits from or issue debt to the public, it is financed by the government through the budget with all appropriations, allocations, financing and guarantees properly and explicitly accounted for in the budget and approved by congress.

- Amendments to the Securities Market Law (2001). Aimed at promoting the development of the securities market by making it more transparent, efficient and accessible. The 2001 amendments enhanced information, disclosure, minority stockholders rights; improved corporate governance practices; introduced a new versatile instrument (certificado bursatil), a security note that can be issued by private and public debtors; incorporated the central counterparty (lender and borrower rights and obligations in securities transactions) to the market structure, reducing systemic risk in the securities market; introduced a consolidated regime applicable to public companies; redefined the functions and responsibilities within the corporate structure; introduced audit and corporate governance committees with independent Board members; included clear mandates and fiduciary duties for Board members, managers and external auditors, and further improved minority shareholder rights. It also it promoted access to abroad securities market to small- and medium-size firms through new corporate vehicles.

- Mutual Fund Law. Aimed at facilitating access to the stock and debt market by a wider range of investors. It improved mutual funds corporate governance practices; allowed for a mutual fund to change from one mutual fund operator to another, to promote competition and to reduce investment manipulations not associated to maximizing the investors' returns; allowed for a more flexible investment regime; and prohibited banks and investment banks to act as mutual fund operators but allowed them to carry out this function by establishing a subsidiary.

- Amendments to the Law of Mutual Insurance Institutions and Associations and the Federal Sureties Institutions Law. Aimed at strengthening the institutional and regulatory framework for the activities of insurance institutions; increasing the efficiency of insurance institutions' operations; consolidating the insurance sector's legal framework with that in place for the financial sector; and developing best corporate practices among intermediaries. Recently, a new amendment introduced the Mortgage Credit Insurance (Seguros de Crédito a la Vivienda) and Financial Warranty Insurance (Seguros de Garantía Financiera).

- Modernization of the legal framework that applies for Sofoles, leasing and factoring companies. Aimed at enhancing competition in the credit market, reducing administrative costs, and fostering the legal framework that applies to financial leasing, factoring and credit. This reform included the deregulation of leasing and factoring activities.

- $\quad$ Amendments to the Income Tax Law. Established a fiscal regime that allows for the development of two investment vehicles, the FIBRAS (Fideicomiso de Infraestructura y Bienes Raices), a vehicle similar to the Real Estate Investment Trusts in the U.S., and private equity vehicles. 
- Amendments and Additions to the Retirement Savings System Law. Opened the possibility for more workers to access the benefits of the New Pension System, including workers not registered in the social security institute (workers affiliated with the social security system for public sector employees, state and municipal governments, and public universities or working independently); allowed complementary contributions for retirement for all workers; and allowed investing, up to a limit of 20 percent, in foreign securities.

- $\quad$ Payment System Reforms. Revamped the legal framework by enacting a Payment Systems Law, in order to ensure payment finality and improve the execution of collateral and the oversight powers of the BOM; eliminated remaining credit risks in the large value payment systems, in line with the BIS CPSIPS; improved the quality of collateral associated with BOM's credit; and consolidated the intraday credit into one payment system (from the previous three systems).

- New Securities Market Law (2005). Established a regulatory framework in line with international standards covering several aspects of the market, such as disclosure of information to investors, minority rights and sound corporate governance. This framework supports the access of mid-sized corporations into the securities market, consolidates the rules applicable to issuers, in order to improve their organization and operations, through modern corporate structures and revamped liabilities. The new law updates the legal framework applicable to securities firms and those financial entities that participate in this sector, such as securities depository entities and central counterparties, among others. The law also seeks to update the regime of criminal offences and redefine the powers of financial authorities in order to make their functioning more efficient. The CNBV is enabled to inform to the general public the existence of inquiries and sanctions imposed. 


\section{DETAILED FSAP UPDATE RECOMMENDATIONS}

\section{A. Short Term}

\section{Financial stability and derivatives markets}

- $\quad$ Strengthen monitoring of credit risks associated with consumer and mortgage lending.

- $\quad$ Continue to strengthen the monitoring of banks' liquidity and contagion risks.

- Better coordinate the design of stress scenarios within the BOM, between the CNBV and the SHCP, and among supervisors and banks, to improve the analysis of financial system-macro shocks linkages.

- Develop continuity plans in conjunction with the private sector.

- $\quad$ Publish the BOM's stability report.

- Allow other institutions to borrow securities from the BOM and allow pension funds and mutual funds to loan securities to make repo markets more liquid.

- $\quad$ Continue attracting participants to MexDer, including by allowing insurance companies to access OTC derivatives market, for hedging purposes, having in place an appropriate regulatory framework for their use to ensure that risks arising from these transactions are acceptable.

\section{Financing of the private sector and competition in credit markets}

- Include in the credit bureau the performance record of SMEs whose loans are currently recorded as invoice discounting with large corporations in bank balance sheets.

- $\quad$ To avoid conflict of interest, credit bureaus should not be owned by users of their services (e.g., commercial banks).

- $\quad$ Promote greater competition across different credit providers through the development and disclosure of standardized interest rate indicators by type of loan product and by provider.

- $\quad$ Evaluate the effectiveness of development bank lending and partial guarantee programs for SMEs.

\section{Development and competition in retail payments systems}

- $\quad$ Promote access of households to the banking sector by enlarging the scope of present payroll schemes, improving the possibilities of bill payment services, and promoting competition on fees and services.

- $\quad$ Foster consumer mobility by enlarging employee freedom to choose banks and removing present limitation under existing payroll schemes.

- $\quad$ Promote the use of common products (e.g., direct debits and payroll schemes) via CECOBAN.

- $\quad$ Ensure interoperability and promote economies of scale. 
Organizational arrangements for financial system policy, regulation, and supervision

- $\quad$ Realign regulatory functions by shifting most regulatory powers from the SHCP to the Commissions, following the precedent established for securities regulation by the New Securities Markets Law.

- $\quad$ Further strengthen coordination among regulatory agencies through strong memoranda of understanding that set out clear responsibilities and accountabilities.

\section{Pensions}

- Individualize ranking of funds in individual statements on the basis of absolute peso amount of yearly fees and the amount of fees the worker would have paid had he/she been in another AFORE.

- $\quad$ Gradually move to promoting competition on net returns.

- $\quad$ Consider further centralizing in the PROCESAR those AFORE functions (e.g., record keeping and back-office account maintenance and management) that are subject to economies of scale.

- $\quad$ Further discourage the use of fees on contributions and shift focus towards promoting competition on net (risk-adjusted) returns.

\section{Disability insurance}

- $\quad$ Enhance transparency in choosing benefits under the old and new system by putting in place a comprehensive election system for disabled workers.

- Clarify the IMSS' solvency concerns in the line of disability insurance and ensure that the IMSS be indifferent to whether disabled workers choose benefits under the old or the new system.

\section{Development banks}

- $\quad$ Establish a subsidy and guarantee bureau.

- Further rationalize operations of development banks.

\section{Housing finance}

- $\quad$ Establish plans for orderly consolidation of mortgage Sofoles once the SHF stops second-tier lending.

- $\quad$ Maintain the 2009 sunset date for SHF second-tier lending to fund middle- and high-income housing.

- $\quad$ Encourage FOVISSSTE to follow INFONAVIT by voluntarily accepting CNBV supervision.

- Implement an integrated, centralized subsidy policy. 
- $\quad$ Foster the reduction of costs that hamper secondary housing markets.

\section{IPAB issues}

- Seek a suitable formula to alleviate the financial condition of IPAB, including the transferring of IPAB's debt to the federal government.

- $\quad$ Consider market-discipline supporting measures for deposit insurance such as a reduction in coverage and the charging of risk-based premiums.

- $\quad$ Establish an effective framework for the liquidation of banks and enable partial deposit transfers under P\&As.

- Introduce interagency contingency planning and develop internal protocols regarding emergency liquidity assistance.

\section{B. Medium to Long Term}

\section{Financing of the private sector and competition in credit markets}

- $\quad$ Set up the preconditions (especially improved information) for a local credit derivatives market.

- Explore potential simplifications of the regulatory environment related to SME lending without undermining prudence.

- Improve information collection to facilitate the analysis of private sector financing and competition in credit markets (identification and quantification of unofficial domestic financing sources, more detailed information on bank revenues by loan product, and analysis of the relationship between developments in the real sector and financing patterns).

- $\quad$ Strengthen state registries of commerce and property and reduce their user cost (notaries).

- $\quad$ Strengthen and harmonize the enforcement of creditor rights across different legal jurisdictions.

\section{Pensions}

- $\quad$ Continue to reform governance and ownership of PROCESAR and then further concentrate in it those AFORE functions that are subject to economies of scale while promoting competition among AFOREs in the retail function of asset management.

- Consider transferring the contributions to INFONAVIT to the RCV account.

- $\quad$ As the market for annuities grows, consider issuing zero coupon CPI-indexed government bonds as well as longevity bonds to facilitate asset-liability matching of companies of life insurance companies.

- Allow specialized annuity providers to use OTC derivatives to hedge risks, subject to appropriate risk management standards. 
- $\quad$ Consider modifying duration matching requirements for annuity providers by introducing key rate duration metrics (to enable hedging against nonparallel shifts in the yield curve).

- Consider relaxing the inflation matching requirements for short term liabilities.

- Streamline regulations in order to minimize inconsistencies and barriers to innovation and competition.

\section{Development banks}

- $\quad$ Further consolidate the system of development banks.

- $\quad$ Redefine mandates of development banks, where needed, and continue with reforms to gradually convert development banks into development agencies.

- Develop and implement indicators to better measure and reward performance of development banks in line with the redefinition of mandates and emergence of new instruments.

\section{Organizational arrangements for financial system policy, regulation, and supervision}

- $\quad$ Establish full consolidated supervision of financial conglomerates.

- $\quad$ Achieve political and budgetary autonomy of regulatory commissions.

- Consider possible consolidation of regulatory commissions. 


\section{Stress AnAlysis FOr COMMERCIAL BANKs, THE INSURANCE SECTOR, AND THE DERIVATIVES EXCHANGE}

\section{A. Liquidity Management and Contagion Analysis for Commercial Banks}

\section{Commercial banks and their supervisors monitor liquidity risks both under} normal and stress scenarios. For instance, the BOM classifies assets and liabilities according to their remaining maturity and computes, regularly, each bank's liquidity gap at the 8- and 30-day time intervals. Under "a normal scenario," the BOM assumes that the withdrawal of deposits each bank faces in a month is equal to the maximum drop in deposits it has experienced during the last nine years, while (based on internal analysis of the stability of each bank deposits) the rest of the deposits are assumed to be fairly stable. The stress scenario focuses on an idiosyncratic run of large depositors (i.e., those with balances exceeding the insured limit). Specifically, under a stress scenario, all large demand deposits are assumed to be withdrawn within 30 days, while time deposits are assumed to be held to maturity. The BOM's estimates suggest an adequate and stable liquidity buffer, even under the noted stress scenario (Figure 9). Also, as shown in the financial soundness indicators (Table 2), the proportion of liquid assets to total assets, and to short-term liabilities continues to be at high levels and stable. ${ }^{23}$

Figure 9. Mexico: Asset/Liability Ratio for Commercial Banks (In percent)

A) Normal Scenario

A/L for 30-day maturity band

(three-month moving average)

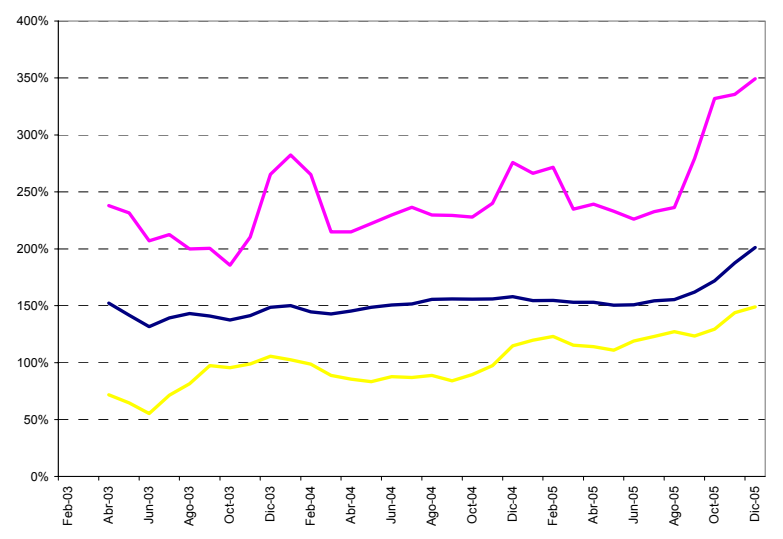

B) Stress Scenario

A/L for 30-day maturity band (three-month moving average)

Source: BOM.

Note: For the system (middle), and for the highest (top) and lowest (bottom) ratios of the system.

\footnotetext{
${ }^{23}$ It would also be useful to combine the analysis of the hypothetical run on deposits with a shock on interest rates, given that liquidity stress scenarios are often associated with increases in interest rates. The analysis of liquidity risk under stress scenario could also be strengthened by introducing a less favorable assumption on withdrawals of time deposits.
} 
121. The BOM also carries out contagion analysis on a regular basis. Efforts by the BOM to evaluate interbank contagion have focused on the analysis of interbank exposures, including net loans, securities, credit lines, foreign exchange transactions and net positions in OTC forwards. The BOM constructs a matrix of bilateral daily bank exposures and based on this matrix it can trace the impact of the hypothetical failure of each bank on the rest of the system, assuming different recovery rates. A bank failure is seen as leading to contagion when it triggers the fall in the capital adequacy ratio (CAR) of one or more institutions below 4 percent. Based on daily data for 2005, the degree of contagion in the banking sector did not appear systemic given that a relatively small number of institutions, representing a small share of the sector's assets, would end up with a CAR below 4 percent.

\section{B. Supplementary Information on Stress Tests for Commercial Banks}

\section{Credit risk}

\section{The assessment of credit risk by BOM was based on a forward-looking}

methodology developed in house. The analysis focused on shocks to default rates of the corporate sector. The activities considered comprised: agriculture; commerce; construction; communications and transportation; services; and industrial activity. Relying on data from Servicio Nacional de Información de Créditos Bancarios (SENICREB), default rates for these sectors were estimated for December 2005. These default rates were stressed proportionally, based on the default rates observed during the 1994-96 crisis, for all economic sectors and within each bank in a cumulative fashion for 18 consecutive months. These stressed corporate default rates were then used to estimate default probabilities and pair-wise correlations for all economic sectors within a bank. A one-month horizon credit VAR was then calculated for each of these eighteen months. Assuming that the portfolio loss distribution can be characterized by its mean and its variance and that the vector of default probabilities and the default co-variance matrix are given exogenously, the value at risk of the loan portfolio delivers the expected and unexpected losses. Analysis of the CAR computed considering the six month cumulative expected losses (to match the peak of the 1994 crisis) shows that at the peak of the stress event (six months after the initial stress trigger), two small banks could see their CAR falling under the regulatory 8 percent (Table 6). It is important to note that for these stress tests, no specific assumptions are made regarding exchange rate, interest rates or stock market value changes. Instead, for these stress tests, the focus is on replicating proportional probabilities of default.

\section{Market risk}

\section{“Peer" scenario}

123. Additional stress tests confirm that the system is resilient to market risk shocks. The CNBV performed a "peer" scenario to assess market risk. The exercise consisted of combining a set of single hypothetical shocks. The shocks were based on the historical volatility observed in a set of peer countries' macro variables that included: country risk, the USD bilateral exchange rate, and short term interest rates. The countries analyzed were those with similar S\&P sovereign debt rating (namely $\mathrm{BBB}-, \mathrm{BBB}$ and $\mathrm{BBB}+$ ) and comprised Bulgaria, Croatia, Malaysia, Poland, South Africa, and Tunisia. In particular, the peer macro 
scenario consisted of assessing the sensitivity of the banking sector's trading books to valuation changes from simultaneous shocks and tracking the resulting impact on the system's CAR. The shocks included a combination of a 180 EMBI+ spread, a 30 percent depreciation in the exchange rate, an increase of $600 \mathrm{bp}$ in the short term (Cete 28) interest rate, and a drop in the U.S. dollar-peso exchange rate by 30 percent. Under this "peer" scenario, the system's CAR would go down to about 12.9 percent (Table 7).

\section{Recommendations}

124. The authorities could introduce some improvements to strengthen the stability

analysis. First, it would be advisable to increase coordination between the research and credit risk units of BOM, and between the CNBV and the treasury's macro unit, in the design of top-down approaches. In order to cross-check the stress tests results of BOM and CNBV, these institutions could coordinate with commercial banks on the choice of a specific set of shocks and scenarios to be analyzed with the banks' own methodologies and request the results of these tests. Second, although the authorities have accumulated significant knowledge on analyzing corporate credit risk, more needs to be done regarding credit risk arising from consumer and mortgage lending. Such credit still represents a low share of commercial banks' assets (on average around 15 percent) and household indebtedness to household disposable income (17 percent) is still moderate, limiting credit risks associated to these sectors. Nevertheless, given these credits' recent fast growth, the authorities are well aware of the need to analyze these risks more closely.

\section{Insurance Sector}

125. The insurance sector (life and non-life) appears resilient to severe shocks. The CNSF conducted a series of sensitivity tests and scenario analysis based on forward-looking, dynamic solvency testing models developed internally. Individual shocks and scenarios included: no premium growth in nominal terms (premium shock); an interest rate drop by 190 basis points in peso rates, reductions of 114 basis points in UDI (inflation-indexed) rates and 114 basis points in the reference foreign interest rate; premiums shock plus loss rate increases; and premium shock plus interest rate shock plus loss rate shock. Under the combined scenario, the number of insurance institutions with a solvency ratio below 1 percent increases from four as of December 2005 to 11, but these represent only about 7 percent of the market solvency requirement (Table 10).

\section{E. Derivatives Exchange}

126. MexDer carried out a stress test to estimate the maximum loss associated with a stress scenario consisting of: a depreciation of the peso-U.S. dollar exchange rate of 100 percent; a drop in the IPC of 15 percent; an increase in Cete 91 by 360 basis points; and an increase in the TIIE of 270 basis points. Assuming different levels of default on this loss, MexDer finds that the resources in each clearing trust in default and those belonging to the same financial group, would have sufficed to stem the problem without ASIGNA having to mutualize any of the losses or to use its own equity. Thus, MexDer's five-step contingency plan appears adequate. In case of a default on the loss under a stress scenario, MexDer's contingency plan calls for: (a) drawing from the resources of each of the clearing trusts in default; (b) drawing 
on the resources of other clearing trusts; (c) ASIGNA using the resources of the clearing fund; (d) ASIGNA requiring the mutualization of the loss using the resources of the rest of the clearing trusts and their minimum equity; and (e) ASIGNA contributing from its own equity, if necessary. 


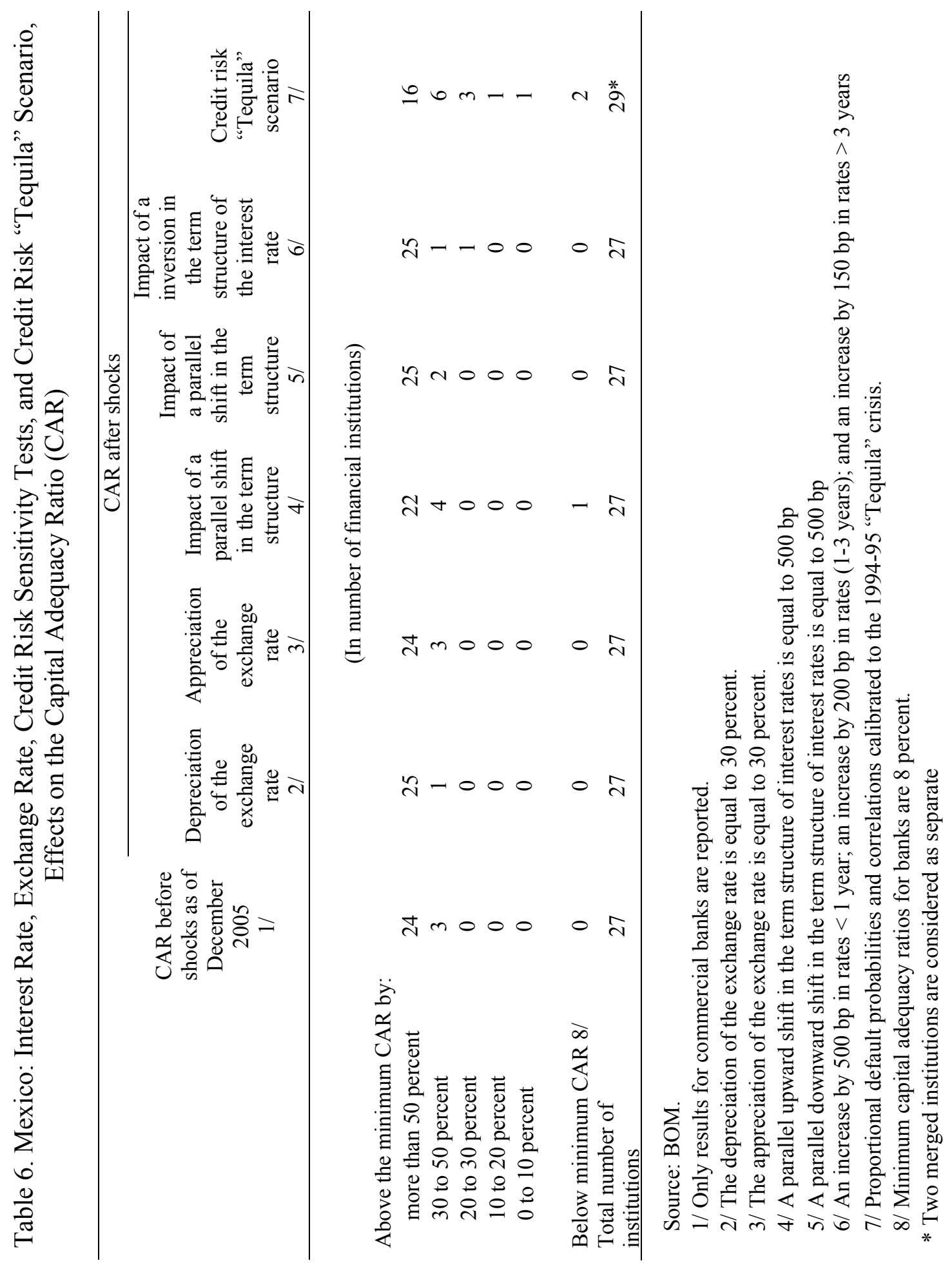




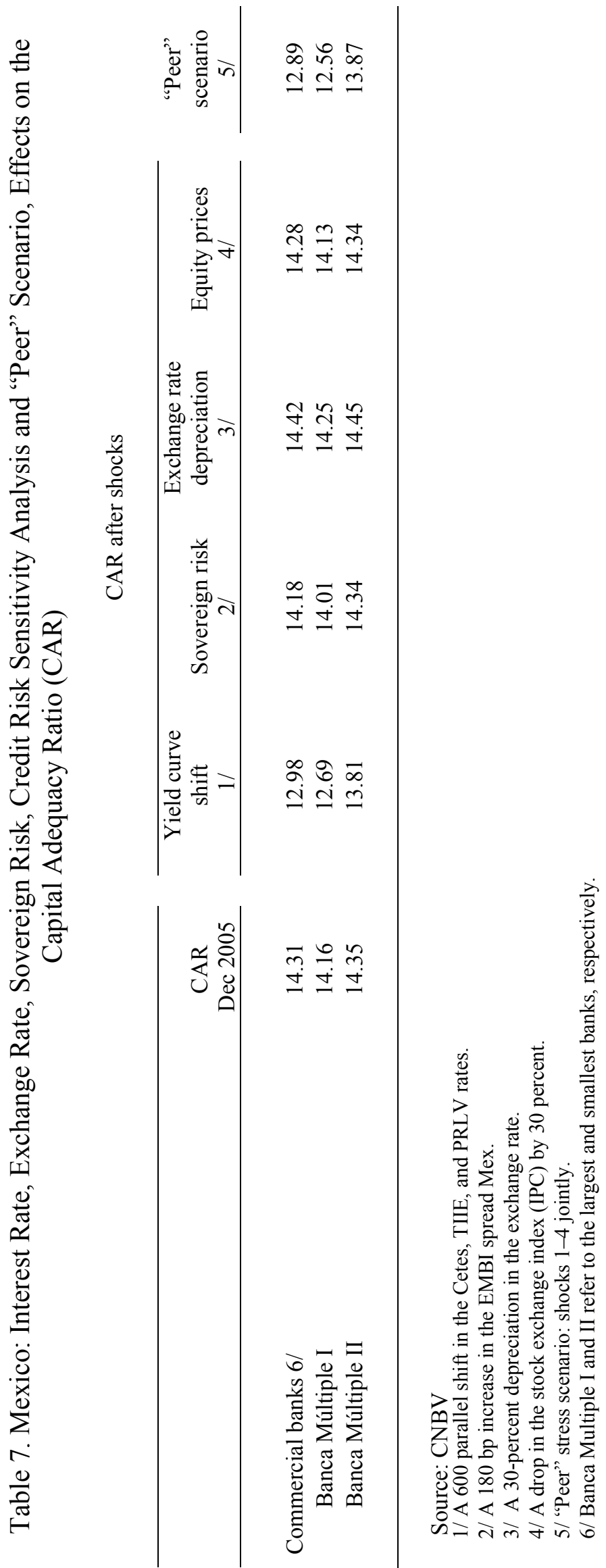




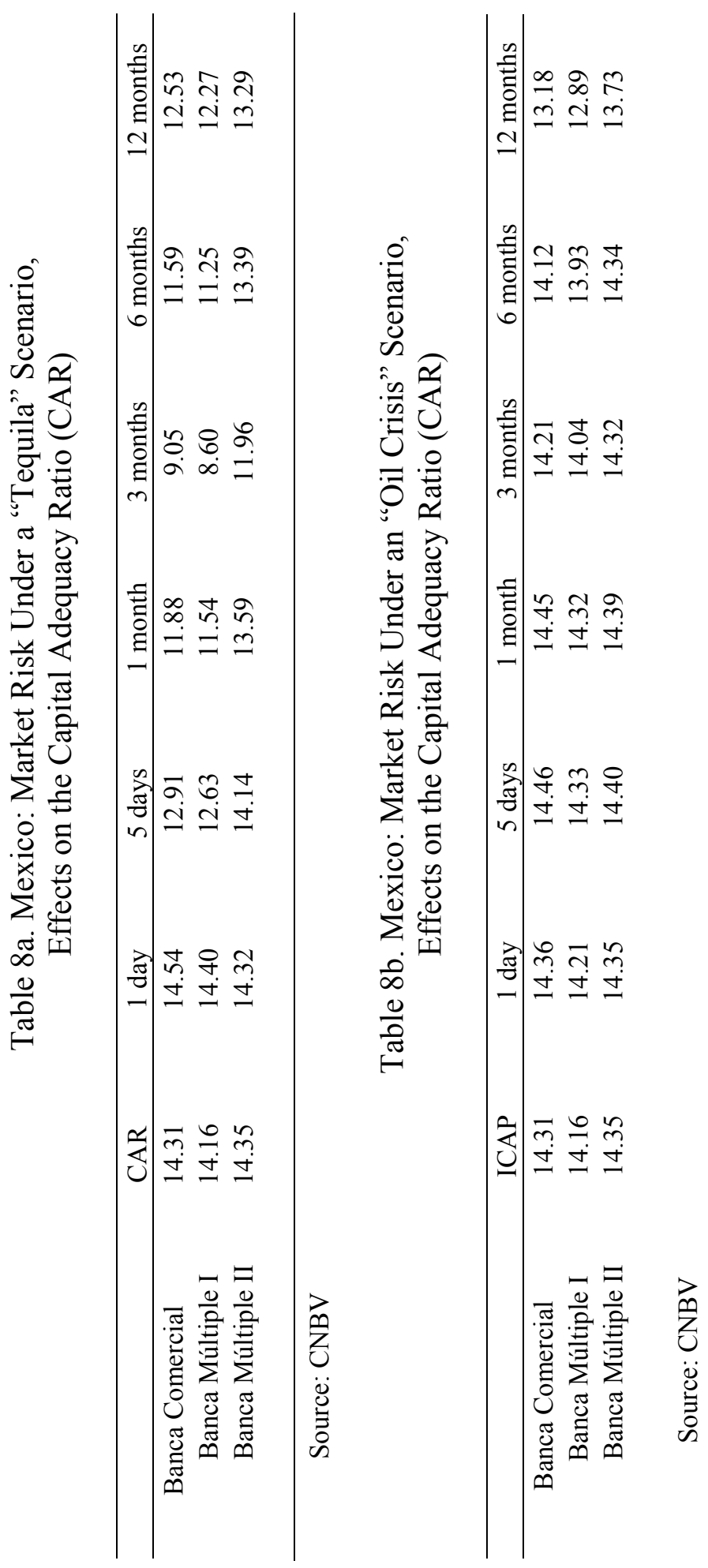


Table 9a. Mexico: Assumptions for Market Risk, “Tequila” Scenario (In percentage change of average rates)

\begin{tabular}{lrrrr}
\hline Variable & $\begin{array}{r}\text { Less or equal } \\
\text { to 1 month }\end{array}$ & 3 months & 6 months & 1 year \\
\hline Mexican stock market price index & 1.49 & -28.25 & -9.14 & 28.27 \\
Exchange rate 1/ & 32.75 & 77.32 & 56.41 & 89.41 \\
Treasury certificates 2/ & 69.48 & 413.68 & 173.22 & 171.70 \\
U.S. T-bills & 2.04 & -0.02 & -0.10 & -0.18 \\
U.S. bonds 3/ & & & & \\
$\quad$ Medium term & 0.96 & -11.84 & -25.81 & -31.63 \\
$\quad$ Long term & 0.46 & -10.99 & -27.44 & -34.46 \\
LIBOR rate in U.S. dollars 4/ & & & & \\
$\quad$ Short term & 1.40 & 3.16 & 2.11 & -3.16 \\
$\quad$ Medium term & 0.56 & -5.75 & -13.48 & -18.82 \\
$\quad$ Long term & 0.76 & -13.10 & -27.36 & -33.83 \\
LIBOR rate in other currencies 4/ & & & & \\
$\quad$ Short term & 2.61 & 8.03 & -6.58 & -18.92 \\
$\quad$ Medium term & 0.90 & -3.37 & -20.33 & -32.16 \\
$\quad$ Long term & 1.43 & -7.46 & -23.08 & -31.88 \\
U.S. stock markets price indices 5/ & 0.99 & 8.44 & 21.47 & 36.42 \\
Consumer Price Index (domestic) & 1.25 & 13.86 & 32.73 & 52.75 \\
\hline
\end{tabular}

Source: CNBV.

1/ Mexican pesos per U.S. dollar.

2/ Mexican treasury certificates with maturity of less than one year.

3/ Medium-term bonds with maturities of 1 to 5 years; and long-term bonds of more than five years.

4/ Short term defined as less than 30 days; medium term, from 30 to 360 days; and long term, above 360 days to 20 years.

5/ Comprises average value for Nasdaq, Dow Jones, and S\&P 500 price indices. 
Table 9b. Mexico: Assumptions for Market Risk, "Oil Crisis” Scenario (In percentage change of average rates)

\begin{tabular}{lrrrr}
\hline Variable & $\begin{array}{r}\text { Less or equal } \\
\text { to 1 month }\end{array}$ & 3 months & 6 months & 1 year \\
\hline Mexican stock market price index & -3.46 & -5.69 & -16.45 & -24.38 \\
Exchange rate 1/ & -0.22 & 5.26 & 11.14 & 22.47 \\
Treasury certificates 2/ & -4.04 & 6.01 & 7.80 & 73.29 \\
Equilibrium interbanking interest rate 3/ & -3.36 & 3.89 & 4.47 & 91.38 \\
Bills 4/ & -4.13 & 2.87 & 6.89 & 73.95 \\
Real interest rate 5/ & -0.24 & -5.80 & -16.96 & -20.59 \\
U.S. T-bills & -2.05 & -3.13 & -2.30 & -16.88 \\
U.S. bonds 6/ & & & & \\
$\quad$ Medium term & -4.52 & -5.39 & -6.74 & -25.96 \\
$\quad$ Long term & -4.79 & -6.42 & -9.85 & -25.16 \\
LIBOR rate in U.S. dollars 7/ & & & & \\
$\quad$ Short term & -2.22 & -4.09 & -5.40 & -5.94 \\
$\quad$ Medium term & -2.42 & -4.30 & -4.78 & -14.39 \\
$\quad$ Long term & -3.79 & -5.25 & -6.68 & -18.39 \\
LIBOR rate other currencies 7/ & & & & \\
$\quad$ Short term & & & & \\
$\quad$ Medium term & 0.30 & 2.89 & -0.69 & -5.77 \\
$\quad$ Long term & 0.14 & -1.99 & -1.30 & -11.62 \\
U.S. stock markets price indices 8/ & -2.52 & -6.45 & -10.06 & -24.05 \\
Consumer Price Index (domestic) & -2.72 & 8.58 & 13.17 & 19.28 \\
& 0.76 & 5.49 & 8.60 & 17.43 \\
\hline Sourc: CNBV. & & & &
\end{tabular}

Source: CNBV.

1/ Mexican pesos per US dollar.

2/ Mexican treasury certificates with maturity from 1 day to 10 years.

3/ From 1 month to 10 years.

4/ Bills payable at maturity from 1 day to 10 years.

5/ From 1 month to 3 years.

6/ Medium-term bonds with maturities of 1 to 5 years; and long-term bonds of more than five years.

7/ Short term defined as less than 30 days; medium term, from 30 to 360 days; and long term, from 360 days to 20 years.

8/ Comprises average value for Nasdaq, Dow Jones, and S\&P 500 price indices. 
Table 10. Mexico: Shocks on Premiums, Return and Loss Rate, and Scenarios, Effects on the Solvency Ratio 1/

\begin{tabular}{|c|c|c|c|c|c|}
\hline & \multirow[b]{2}{*}{$\begin{array}{c}\text { Solvency } \\
\text { ratio as of } \\
\text { December } \\
2005\end{array}$} & \multicolumn{4}{|c|}{ Solvency ratio after shocks } \\
\hline & & $\begin{array}{c}\text { Premiums } \\
\text { shock } \\
2 /\end{array}$ & $\begin{array}{c}\text { Interest } \\
\text { rate } \\
\text { shock } \\
3 /\end{array}$ & $\begin{array}{c}\text { Loss } \\
\text { rate } \\
\text { shock } \\
4 /\end{array}$ & $\begin{array}{c}\text { Combined } \\
\text { scenario } \\
5 /\end{array}$ \\
\hline \multicolumn{6}{|l|}{ Solvency ratio in number of insurance companies: } \\
\hline of between 1.3 and 1.5 & 4 & 0 & 0 & 0 & 3 \\
\hline of between 1.1 and 1.3 & 4 & 4 & 2 & 1 & 1 \\
\hline of between 1.0 and 1.1 & 5 & 4 & 5 & 5 & 4 \\
\hline of below 1 & $46 /$ & 8 & 9 & 10 & 11 \\
\hline $\begin{array}{l}\text { Percentage of insurance companies below } \\
\text { below solvency ratio of } 1\end{array}$ & 6.7 & 13.3 & 15 & 16.7 & 18.3 \\
\hline \multicolumn{6}{|l|}{ Capital insufficiency } \\
\hline as percentage of market solvency requirement & 1.3 & 2.7 & 3.4 & 5.7 & 7.3 \\
\hline
\end{tabular}

Source: CNSF.

1/ Solvency ratio is defined as assets covering capital requirement to capital requirement.

2/ No premium growth in nominal terms.

3/ Premiums shock + Interest rate fall from current values to: Mexican pesos (5.5 percent), foreign currency (4.0 percent), and indexed currency (3.5 percent).

4/ Premiums shock + Loss rate increase: Life (10 percent), Accidents and Health (13 percent), Property \& Casualty (20 percent), Automobile (5 percent), Catastrophic risks (10 percent).

5/ Premiums shock + Interest rate shock + Loss rate shock.

6/ Insurers with solvency ratio below 1 as of December 2055 are currently subject to regularization plans in order to meet regulatory requirements. 


\section{Payments ANd Securities Settlement IsSUeS}

127. An update of progress in meeting the standards of the CPSS Core Principles for Systemically Important Payment Systems (CPSIPS) was conducted as part of the 2006 FSAP Update mission. The Mexican authorities provided the FSAP team with a note in which they explained how they have followed up on the recommendations of the 2001 FSAP and the way the risks in the payment infrastructure, as indicated by the FSAP team, were addressed. The update of 2006 focused on the assessment of the measures taken and no new assessments were carried out.

\section{Institutional and market structure}

128. Since 2001 the Mexican infrastructure for large value payment and securities settlement has been modernized and its safety and soundness improved substantially.

129. The implementation of the Payment System Law in December 2002 was an important milestone for upgrading the legal basis for payment and settlement systems. This law regulates: (a) the finality of payments in systemically important payment and settlement systems; (b) the protection of netting schemes and the collateral arrangements to ensure timely settlement and to facilitate liquidity management in payment and settlement systems; and (c) the oversight power of the BOM. In addition, the BOM has issued regulation to support check truncation, the use of electronic signatures, and regulation that endorse the development and implementation of new payment instruments.

130. In the area of retail payments, progress was made to improve the fragmented infrastructure and enlarge the connectivity and interoperability of the different networks of commercial banks. The clearing and settlement of checks and electronic fund transfers with deferred value date (EFTs), is now concentrated in CECOBAN, an automatic clearing house $(\mathrm{ACH})$ owned by the banking sector. The centralization of the clearing of checks, made possible by imaging and check truncation, is completed and CECOBAN is now expanding its activities in the EFT market, especially credit transfers. However, with a market share of 50 percent, checks are still the most used noncash payment instrument. Debit and credit card transactions are growing rapidly, although from a relatively low level. Most of the debit cards are only used to withdraw cash from ATMs. Card payments and withdrawal of cash from ATMs by clients of other banks are cleared and settled via two switches, e-GLOBAL, owned by the two largest banks, and PROSA (Promoción y Operación S.A. de C.V.) which is owned by most of the other banks with a sizeable participation in the card business.

131. Notwithstanding these improvements, the banking sector still reaches only a relatively small part of the household sector and the infrastructure for retail payments is still underdeveloped compared to countries in the region or in the same phase of development.

132. In the area of large value payments SPEI, a modern hybrid system, replaced the SPEUA in 2005. The SPEUA was a system that used mutual credit lines between each of the 
participants (the sum of the credit lines granted to a participant formed the debit cap or the amount of overdraft allowed in his account) and with an explicit guarantee of the BOM to settle the clearing results at the end of the day in SIAC, even if this would result in uncollateralized overdrafts in the latter system. ${ }^{24}$ In the new system SPEI, neither the other participants, nor the BOM, grant any credit lines. No overdraft is allowed in the system and the participant bank has to manage the liquidity in its account by transferring sufficient liquidity from its BOM account at the opening of the system or during the day, if additional liquidity is needed, via an efficient liquidity bridge between SIAC and SPEI.

133. SPEI, a system that effectively combined the characteristics of a real time gross settlement system with the liquidity savings of a multilateral netting system, is the central system for the settlement of large value payments and urgent client-to-client payments in Mexico. SIAC is mostly used for monetary policy transactions, the execution of intraday repos for liquidity management in the payment and securities infrastructure, the withdrawal of banknotes, and government payments.

\section{For equity transactions conducted on the Stock Exchange a Central} Counterparty (CCP) was established to contain the risks in this type of securities transactions. The CCP settles in SIDV. For transactions conducted on MexDer, the derivatives exchanges are cleared and settled via ASIGNA (Asigna Compensación y liquidación), which also acts as a central counterparty.

135. A redesign of the SIDV is envisaged in the near future. One of the objectives of the restructuring is to enlarge the operational reliability of the system.

\section{Progress in meeting the CPSIPS}

136. The main deficiencies observed in the 2001 FSAP were related to the legal basis and the management of credit and liquidity risks.

137. With respect to the legal basis the mission recommended in 2001 to improve: (a) the finality of payments; (b) the legal basis for collateral arrangements and the possibilities to realize the collateral immediately in case of a default; (c) the recognition of electronic payments and the use of electronic signature; (d) the legal basis for check truncation and new payment instruments; and (e) the oversight powers of the BOM.

138. Finality of payments. Since December 2002, finality of payments in a systemically important payment system (SIPS) is regulated in chapter II of the Payment System Law. All payments in SIPS are final and payment orders accepted by the systems are irreversible. Resolutions from judicial or administrative authorities (including those derived from the application of the Bankruptcy Law) to prohibit, suspend, or limit payments through a SIPS will only become effective one day after the SIPS administrator has been notified. Payment

\footnotetext{
${ }^{24}$ In case the participant was not able to redeem the uncollateralized overdraft three days in a row, the BOM could reclaim some of the losses from the surviving participants in proportion to the bilateral credit lines granted to the defaulted participant. However, the loss sharing in SPEUA did not foresee multiple defaults. In that case the risk had to be borne solely by the BOM.
} 
orders sent in on the day the notification is received will be executed normally as long as there is sufficient liquidity in the account of the involved participant. In case of fraud or unfair preferential treatment of certain creditors, payments during the suspect period can be claimed back, but only outside the system. Within this context the judicial authorities cannot unwind payments settled in a SIPS. Moreover, bank accounts at the BOM cannot be seized by judicial or administrative authorities.

139. A sound legal basis for collateral arrangements. The BOM has improved its collateral arrangements substantially. Nowadays, the BOM uses two instruments to grant overnight or intraday liquidity, namely, pledge of DRMs and repos. The BOM only allows overdrafts in the current accounts or grants overnight credit to banks that have pledged enough DRMs to cover both the principal amount and interest on the credit. The pledge of both DRMs and repos to collateralize loans is fully recognized under Mexican laws. In case of a default the BOM is allowed to compensate immediately its claim with the DRM obligation that has been pledged to secure the loan. In repos, BOM is allowed to sell the underlying securities that have not been redeemed timely or not been rolled-over in a new repo operation.

140. Legal basis for electronic signature and new payment instruments. Electronic transfers and the use of electronic signature are fully recognized and check truncation and new payment instruments as direct debits are fully endorsed under Mexican laws.

141. Oversight responsibilities of the BOM. The Payment System Law of 2002 grants the BOM the power to oversee all systemically important payment and securities settlement systems. The BOM designates each year which systems are systemically important. At present the systems operated by the BOM itself (SIAC and SPEI) and SIDV, the system owned and operated by INDEVAL, are designated and fall within the scope of the oversight policy of the BOM. The Payment Law grants the BOM effective instruments to carry out the oversight task, such as the power to approve the internal rules of the designated systems, request information, and impose adjustment programs or sanction the system provider.

142. As a result of these changes, all the previously observed deficiencies in the legal basis have now been eliminated. Finality, protection of collateral arrangement used by the BOM to secure credit granted in the context of its payment policy, the use of electronic transfers and electronic signature, and the oversight powers of the BOM are now well regulated. Further improvement will be brought forward when the recently approved Law on Banking Insolvency, in which clear rules for closing insolvent banks will be given, is implemented.

143. With respect to risk management, the 2001 FSAP noted that the BOM was exposed to credit risks. The exposure was the result of the explicit settlement guarantee in SPEUA and the policy to allow uncollateralized overdrafts in the framework of credit auctions, the buying of government securities in the primary market, the withdrawal of banknotes and the payment of fees and commissions to the BOM. In addition, the improvement of the risk management of collateral was recommended. 
- Settlement guarantees and uncollateralized credit lines. The explicit settlement guarantee was eliminated with the replacement of SPEUA by SPEI. No overdrafts are allowed in SPEI and if participants need liquidity to settle their payment obligation in this system, they have to conduct an intraday repo with the BOM and transfer the obtained funds via the existing liquidity bridges to their accounts in SPEI. Also the credit lines in SIDV were eliminated and overdrafts are no longer allowed in the context of credit auctions and the issuing of government bonds.

- Improvement of collateral risk management. The collateral arrangements of the BOM in the framework of intraday and overnight credit facilities are improved by: (a) using the repos as the main instrument to collateralize the credit granted;

(b) renewing the list of eligible assets that could be used as collateral; and (c) setting adequate margins. The use of repos has eliminated the problem that liquidation of collateral could be cumbersome and time consuming. The new list of eligible collateral for repos contains only liquid paper while, in the past, explicitly nonmarketable and illiquid paper was used by banks. Only DRMs can be used as collateral on BOM's credit lines.

144. As a result of these changes, most of the risk exposures of the BOM from explicit and implicit guarantees and inadequately collateralized credit lines have now been eliminated. Some less significant credit exposure still exists in the schemes for determining the interbank reference rates (TIIE, Tasa de Interés Interbancaria de Equilibrio) and the cash withdrawal process, due to the fact that not all uncollateralized overdrafts are eliminated. However, modifications to have full collateralization in these schemes will come into effect by mid- 2006 . 